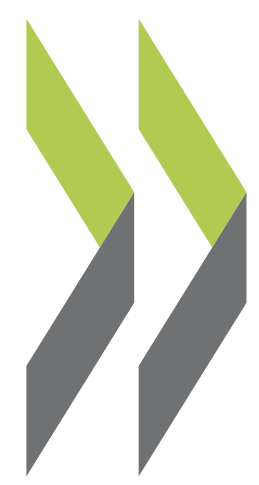

OECD Labour Market and Social Policy Occasional Papers No. 47

Performance Measurement and Performance Management in OECD Jeremy Hurst, Health Systems

\title{
Melissa Jee-Hughes
}




\section{Unclassified}

OECD

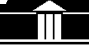
OCDE

通要

Organisation de Coopération et de Développement Economiques

Organisation for Economic Co-operation and Development

DEELSA/ELSA/WD(2000)8

OLIS : 29-Jan-2001

Dist. : 30-Jan-2001

DIRECTORATE FOR EDUCATION, EMPLOYMENT, LABOUR AND SOCIAL AFFAIRS

English text only

LABOUR MARKET AND SOCIAL POLICY - OCCASIONAL PAPERS N ${ }^{\circ} 47$

PERFORMANCE MEASUREMENT AND PERFORMANCE MANAGEMENT IN OECD HEALTH SYSTEMS

Jeremy Hurst and Melissa Jee-Hughes

99202

Document complet disponible sur OLIS dans son format d'origine

Complete document available on OLIS in its original format 


\title{
DIRECTORATE FOR EDUCATION, EMPLOYMENT, LABOUR AND SOCIAL AFFAIRS
}

\section{OCCASIONAL PAPERS}

This series is designed to make available to a wider readership selected labour market and social policy studies prepared for use within the OECD. Authorship is usually collective, but principal writers are named. The papers are generally available only in their original language -- English or French -- with a summary in the other.

Comment on the series is welcome, and should be sent to the Directorate for Education, Employment, Labour and Social Affairs, 2, rue André-Pascal, 75775 Paris CEDEX 16, France. Additional limited copies are available on request.

The opinions expressed and arguments employed here are the responsibility of the author(s) and do not necessarily reflect those of the OECD

\author{
all or part of this material should be made to: \\ Head of Publications Service \\ OECD \\ 2, rue André-Pascal \\ 75775 Paris, CEDEX 16 \\ France
}

Applications for permission to reproduce or translate

Copyright OECD 2000 
DEELSA/ELSA/WD(2000)8

\section{ACKNOWLEDGEMENTS}

The authors of this paper wish to acknowledge the assistance and advice of a network of contributors in national administrations and other institutions. They also wish to thank Peter Scherer and Stéphane Jacobzone for comments on this paper and on an earlier draft. 


\section{SUMMARY}

1. Health systems in OECD countries are under pressure to improve their performance. Against that background, this paper has three main aims:

i. To compare concepts of the 'performance' of health care systems developed by the WHO and by the OECD, with 'performance frameworks' adopted in selected OECD countries.

ii. To compare the key indicators of performance derived from these proposed performance concepts. A secondary objective, here, is to try to identify new performance variables that might eventually be included in OECD Health Data.

iii. To compare and contrast the different performance management arrangements in the selected OECD countries, and to evaluate the extent to which there is evidence that new indicators and new institutions have been brought together successfully to improve performance itself.

2. In order to achieve these aims, the paper reviews the performance frameworks and some of the performance indicators adopted recently by WHO, OECD, Australia, Canada, the UK and the US. In addition, a selective review has been undertaken of performance management experience, mainly in the UK and the US. On the basis of that, the following conclusions have been drawn in relation to each of the objectives set out above:

i. Although there are many commonalties between international organisations and among OECD Member countries concerning concepts of 'performance' for health care systems, agreement is still far from complete. That is partly because of differences in the objectives set for health systems in different frameworks, and partly because concessions are made in some frameworks to the difficulties of operationalising high-level concepts of outcomes and efficiency.

ii. A selective review of the performance indicators/measures being developed by WHO, OECD and each of the four OECD Member countries listed above, suggests that the development of indicators is proceeding at different speeds, in different areas of performance measurement. Relatively slow progress is being made in the area of health outcomes. Moreover, such measures as do exist at a population level are usually proxies. Faster progress is being made with the development of indicators of the responsiveness of health services to consumers. There is slow progress with the development of equity indicators. There is also slow progress with the compilation of overall measures of the efficiency of health systems of a kind that command widespread confidence. The asymmetry of knowledge between health-care professionals, on the one hand, and health-care consumers and lay managers, on the other, seems here to stay for some time to come. Nevertheless, given the effort now being put into collecting performance indicators in many OECD Member countries, there seem to be good prospects for improving coverage of such indicators in $O E C D$ Health Data within the next few years. However, there may be a need for international harmonisation of measures if comparative work is to proceed at an international level.

iii. There are similarities and differences across OECD countries in performance management institutions, using 'performance management' in a broad sense. All countries rely heavily on professional licensure, self-regulation and peer review for controlling the quality of medical and 
nursing care. That is not surprising in view of the asymmetry of knowledge referred to above. Apart from that, the institutions of 'external' performance management differ widely between countries. The optimal role for external scrutiny is not yet well defined. Questions remain about who should be the recipients of performance indicators and what incentives there should be to act upon them. The few evaluations we have of the use of performance indicators suggest that publishing indicators of performance in circumstances where there are incentives to act upon them may indeed have a favourable effect on measured performance. There are signs that providers may be more responsive to such publication than other actors in the health-care system. However, publication can also have unintended and unwanted side-effects. That is probably an inevitable consequence of the fact that the available measures of health outcomes and responsiveness are frail and incomplete. A possible implication is that 'external' review and peer review should be seen as complementary and used in a climate of co-operation. Meanwhile, the search for better indicators of the 'quality', and hence the 'efficiency', of health care is as urgent as ever.

\section{RESUME}

3. Toutes sortes de pressions s'exercent actuellement pour que les systèmes de santé des pays de l'OCDE s'améliorent. Dans ce contexte, on a adopté dans la présente étude trois principaux objectifs, à savoir :

i. Comparer la définition de la performance des systèmes de santé élaborés par l'OMS et l'OCDE avec les cadres d'évaluation de la performance adoptés dans plusieurs pays de l'OCDE.

ii. $\quad$ Comparer les indicateurs clés de performance établis à partir de ces définitions proposées. Un deuxième objectif dans ce contexte, pourrait être d'identifier de nouveaux paramètres de performance qui pourraient éventuellement être inclus dans Eco-Santé OCDE.

iii. Comparer les différents mécanismes de gestion de la performance dans les pays de l'OCDE retenus et faire ressortir les différences ; évaluer dans quelle mesure les faits indiquent que de nouveaux indicateurs et de nouvelles institutions ont été mis en œuvre avec succès pour améliorer la performance elle-même.

4. On a étudié les cadres d'évaluation de la performance ainsi que certains des indicateurs de performance adoptés récemment par l'OMS, l'OCDE, l'Australie, le Canada, le Royaume-Uni et les EtatsUnis. On a en outre examiné le fonctionnement de la gestion de la performance dans certains pays, principalement au Royaume-Uni et aux Etats-Unis. Sur cette base, on a tiré les conclusions ci-après au sujet de chacun des objectifs énoncés ci-dessus.

i. Malgré de nombreux points de convergence entre les organisations internationales et entre les Etats Membres de l'OCDE au sujet de la définition de la «performance » des systèmes de santé, l'accord est loin d'être parfait. Cela tient en partie à ce que les objectifs fixés dans les différents cadres d'évaluation sont différents, mais aussi à ce que certains de ces cadres tiennent compte avec quelque indulgence de la difficulté qu'il y a à réaliser concrètement des définitions de haut niveau des résultats et de l'efficience. 
ii. A en croire une étude sélective des mesures et indicateurs de la performance des systèmes de santé élaborée par l'OMS, l'OCDE et les quatre pays Membres de l'OCDE mentionnés cidessus, la mise au point des indicateurs progresse plus ou moins rapidement selon les domaines. En ce qui concerne les résultats en santé, le progrès est relativement lent. De plus, comme ces mesures se situent au niveau de la population, elles sont généralement des variables représentatives. Le progrès est particulièrement rapide dans le domaine des indicateurs de la réactivité des services de santé aux consommateurs. Pour les indicateurs d'équité, le progrès est moins rapide. On avance aussi plutôt lentement dans la mise au point d'une mesure globale de l'efficience des systèmes de santé qui puisse être acceptée avec confiance. Il semble à cet égard que l'asymétrie des connaissances entre les professionnels de la santé d'une part, les consommateurs et les gestionnaires de l'autre, ne soit pas près de s'estomper. Toutefois, étant donné l'effort actuellement consacré à la collecte d'indicateurs de performance dans beaucoup de pays Membres de l'OCDE, on peut espérer que la couverture de ces indicateurs dans EcoSanté $O C D E$ s'améliorera au cours des quelques prochaines années. Cependant, une certaine normalisation des mesures serait peut-être nécessaire pour permettre des comparaisons internationales.

iii. Les institutions de gestion de la performance des divers pays de l'OCDE présentent des similitudes et des différences -- gestion de la performance étant ici entendue au sens large. Dans tous les pays, le contrôle de la qualité des soins médicaux et infirmiers repose largement sur les permis d'exercer, l'autodiscipline et l'examen par les pairs. Cela n'est pas surprenant étant donné l'asymétrie des connaissances évoquée plus haut. En dehors de cela, les institutions de gestion « externe» de la performance diffèrent beaucoup d'un pays à l'autre. Le rôle optimal des contrôles externes n'est pas encore bien défini. A qui doivent être destinés les indicateurs de performance? Quelles incitations doivent être en place pour assurer qu'il leur soit donné suite? Les rares évaluations dont nous disposons de l'utilisation des indicateurs de performance montrent que la publication de tels indicateurs, lorsqu'il existe des incitations à leur donner suite, peut effectivement avoir un effet favorable sur la performance mesurée. Il semble que les prestataires soient plus sensibles à cette publication que les autres acteurs du système de santé. Mais la publication peut aussi avoir des effets indésirables. Cela est probablement inévitable du fait que les mesures des résultats et de la réactivité sont fragiles et incomplètes. Peut-être faut-il en conclure qu'il est nécessaire d'utiliser à titre complémentaire et dans un climat de coopération des contrôles «externes » et des examens par les pairs. En attendant, il apparaît clairement qu'il faut continuer à rechercher de meilleurs indicateurs de la « qualité »-- et donc de l'« efficience »-- des soins de santé. 


\section{TABLE OF CONTENTS}

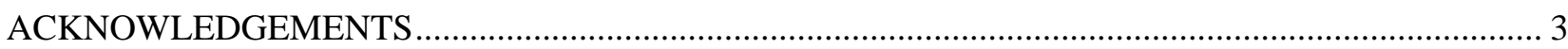

SUMMARY

RESUME

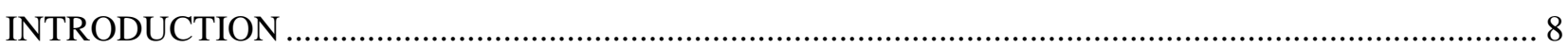

THE PERFORMANCE MEASUREMENT AND MANAGEMENT CYCLE …...................................... 8

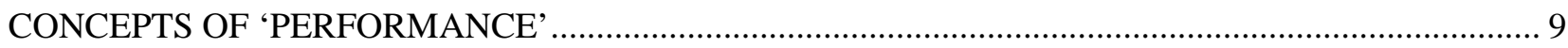

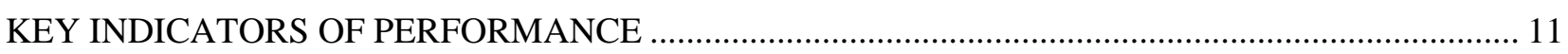

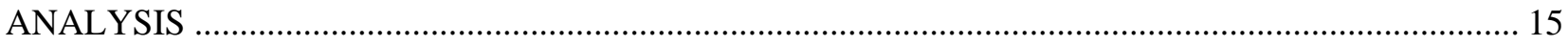

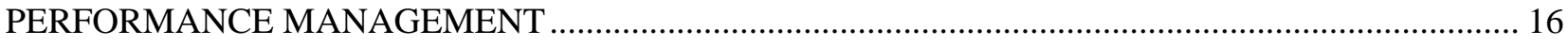

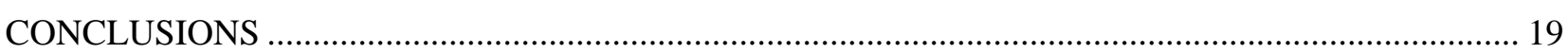

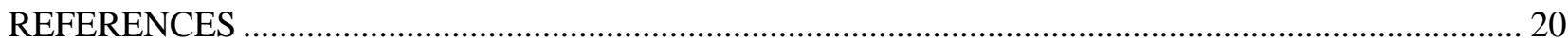

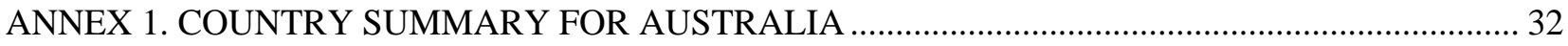

ANNEX 2. AUSTRALIA'S NATIONAL HEALTH PERFORMANCE COMMITTEE'S FRAMEWORK

ANNEX 3. AUSTRALIA'S ACUTE HOSPITAL PERFORMANCE FRAMEWORK ............................ 37

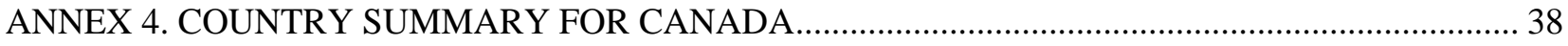

ANNEX 5. CANADIAN INSTITUTE FOR HEALTH INFORMATION'S PERFORMANCE

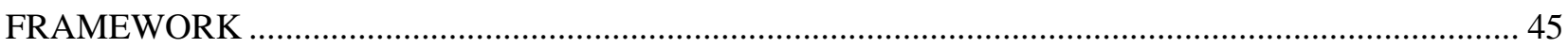

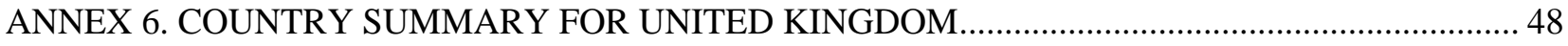

ANNEX 7. NHS HIGH-LEVEL PERFORMANCE FRAMEWORK …................................................... 52

ANNEX 8. COUNTRY SUMMARY FOR THE UNITED STATES ..................................................... 56

ANNEX 9. UNITED STATES' NATIONAL COMMITTEE QUALITY ASSURANCE'S HEDIS

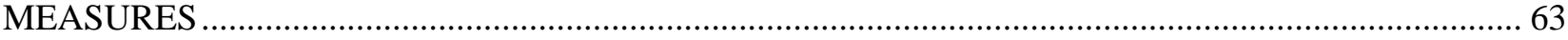

ANNEX 10. US HCFA QUALITY INDICATORS FOR MEDICARE'S HEALTH CARE QUALITY IMPROVEMENT PROGRAM 


\section{INTRODUCTION}

5. There is mounting pressure on health systems to improve their performance. Technological advances and rising consumer expectations continue to raise demand. There is also growing concern about medical errors. Meanwhile, both public and private funders continue to strive to contain costs and control supply. Consequently, there is an intensification of the search for improvements in value for money.

6. In many OECD countries, equity goals for health and for health care have not yet been fully defined, let alone achieved.

7. The result is widespread interest in the explicit measurement of the 'performance' of health systems, embracing quality, efficiency and equity goals and in influencing or managing performance. In some cases efforts are being made to strengthen self-regulation by the providers but in this paper we focus mainly on 'external' scrutiny and management of performance.

8. This paper has three main objectives.

i. To compare concepts of the 'performance' of health care systems developed by the WHO and by the OECD, with 'performance frameworks' adopted in selected OECD countries.

ii. To compare the key indicators of performance derived from these proposed performance concepts. A secondary objective, here, is to try to identify new performance variables that might eventually be included in 'OECD Health Data'.

iii. To compare and contrast the different performance management arrangements in the selected OECD countries, and to evaluate the extent to which there is evidence that new indicators and new institutions have been brought together successfully to improve performance itself.

9. Currently institutions in at least 12 Member countries are developing performance frameworks and performance indicators for their health care systems. In this paper we have chosen to concentrate on the experience of four of these countries. They have been chosen because of the length of their track record or because of the scale of the effort they have put into performance frameworks and performance measurement in recent years.

10. The four countries are Australia, Canada, the United Kingdom and the United States. Annexes 110 provide detailed descriptions of various aspects of the performance frameworks and performance management arrangements that are being developed in each of these countries.

\section{THE PERFORMANCE MEASUREMENT AND MANAGEMENT CYCLE}

11. Chart 1 (adapted from Nutley and Smith, 1998) depicts the cycle of performance measurement and performance management. On the left, is the health care system, for which improvements in performance are desired. At the top, is the conceptualisation and measurement of performance. At the right, is analysis of the data collected. That is required for various reasons such as: discriminating between controllable and uncontrollable variations; constructing composite measures of performance (if desired); 
and setting standards or benchmarks. At the bottom is the activity or management which is necessary to change the behaviour of the health system. That will vary with the institutions concerned. For example, in some systems, the aim may be to inform the choices of consumers or purchasers in a health care market. In other systems the aim may be to inform the decisions of line managers in an integrated public service. The cycle is completed if actions lead to changes in performance. It is possible for these changes to be perverse rather than, or as well as, benign.

\section{CONCEPTS OF 'PERFORMANCE'}

12. A necessary first step in the measurement process is the adoption of a set of objectives for the health system. 'Performance' is the extent to which the system is meeting these objectives. There is no complete agreement about what is meant by the 'performance' of health systems. That is not surprising because the objectives - especially the equity objectives - which can be set for health systems are a political matter, about which nations and individuals may differ. There are also differences between countries in the scope of the 'health systems' to which they propose to apply ideas of 'performance'. OECD put forward initial ideas about a common set of objectives for health care systems in 1992 (OECD, 1992). More recently, WHO has put forward somewhat similar proposals and has devoted its World Health Report, 2000 to reporting estimates of the performance of the health systems of its 191 Member countries against its proposed objectives.

\section{WHO framework}

13. The 'health system goals' proposed by WHO are shown in Table 1. There are three goals: health improvement; responsiveness to the expectations of consumers; and fairness in financial contribution. In addition, there are two types of 'component for assessment' of goal achievement: average level and distribution which are applied to the first two goals (health improvement and responsiveness). This results in five components of health system performance. Efficiency is defined as, "... how well the socially desired mix of the five components of the three goals is achieved, compared to the available resources" (Murray and Frenk, 2000). The level of resources is treated as exogenous - decided outside the health system. The health system itself is defined widely, to embrace all 'health actions' whose primary intent is to improve or maintain health. However, the responsiveness goal appears to be confined to the responsiveness of medical care.

14. The calculations of performance in the WHO World Health Report 2000 involved estimating for each country: actual levels of achievement against the weighted sum of the 5 components; (the weights devoted to each goal being based on a survey of 1006 respondents from 125 countries, half of whom were WHO Staff) ${ }^{1}$; estimating the maximum level of achievement that might be expected given the available resources (on the basis of a multivariate, statistical, 'frontier' analysis); estimating the minimum level of achievement that might be expected if there were no expenditure on health care; and expressing actual goal achievement as a proportion of the difference between maximum and minimum expected goal achievement. The report also carries out these analyses using one component only: health improvement itself. As a result, the WHO report contains a large number of 'performance' scores for each of the 191 member countries: each of the five components, the weighted sum of all five and the 'frontier' analysis

1. The resultant overall index gives predominant weight to distributional components. "Together, the levels of health and of responsiveness receive a weight of three-eighths of the total. The three distributional measures, which together describe the equity of the system account for the remaining five eighths. Countries which have achieved only rather short life expectancies and cannot adequately meet their peoples' expectations for prompt attention or amenities may nonetheless be regarded as having health systems which perform well with respect to fairness on one or more dimensions" [WHO, The World Health Report 2000, p.39]. 
which is calculated for the health improvement score and the overall score. It is the last of these which provided the 'headline' score which appeared in most press reports

15. In the frontier analysis, the level of education (schooling) is treated as the only determinant of health status apart from health expenditure. Such an approach is likely to yield higher estimates of the impact of 'health systems' on health status than approaches which include more non-medical determinants of health, such as standards of living and environmental factors, as explanatory variables (Or, 2000).

\section{OECD proposals}

16. In order to ensure a fruitful dialogue, the OECD has adopted many aspects of WHO's proposed performance framework but OECD also proposes, for OECD use, a few modifications to it. First, the Secretariat considers that 'access' should be a component of 'responsiveness' - mainly to allow questions of equity of access to health care to be addressed within the framework ${ }^{2}$. That is what some of our Member countries have proposed for their own frameworks (see paragraph 36, below). Secondly, it suggests including the level of health expenditure, as a goal. That means the desirable level of health spending can be addressed inside the framework (the desired level of health expenditure was called 'macroeconomic efficiency' in OECD, 1992). Thirdly, OECD does not intend currently to suggest any weighting of goals. Rather, it would seek to report performance on several dimensions. Lastly, OECD work on performance assessment should be devoted mainly to the performance of the health care system, as opposed to public health activities and other wider issues.

17. The effect of the first through to the third of these proposed adjustments to WHO's framework, are shown in Table 2. The revised framework now embodies two concepts of efficiency. 'Microeconomic efficiency', conceptually, would involve comparing the measured productivity of a health system, that is, health outcome and responsiveness per \$, with some estimate of its maximum attainable productivity, for a given level of resources. 'Macroeconomic efficiency' would involve examining how changing the level of resources would bring health outcomes and responsiveness closer to, or further away from, their desired level compared with other goods and services. It must be acknowledged that it is easier to specify such ideas at a conceptual level than it is to put them into operation. (See paragraphs 38-42, below.)

\section{Member country proposals}

18. The four Member countries, on which we are focusing, have themselves put forward various concepts of performance for their health care systems. We have examined two frameworks put forward in Australia (as well as some proposals at State level), two in Canada (as well as some proposals at Provincial level), a series of proposals over time in the United Kingdom, and three in the USA (where there are others). Details of recent proposals are set out in Annexes 1-10. In the case of one of the Australian and one of the Canadian proposals, we have focused on the 'health system performance' sub-section of wider health information frameworks. These wider health information frameworks also cover health status and non-medical determinants of health.

19. It is not easy to compare the WHO, OECD and individual country frameworks at a conceptual level. That is because there are differences in the way terminology has been used for concepts, especially concepts such as 'quality' and 'efficiency'. The WHO and OECD frameworks offer high level concepts whereas the national frameworks show an understandable tendency to put forward concepts which are

2. The WHO explicitly rejects this, arguing that access is a determinant of responsiveness, rather than a component (WHO, 2000, p.24). 
easier to make operational. That has led to more emphasis having been given to structural and process domains in the national proposals than in the proposals from WHO and OECD.

20. Despite these difficulties, an attempt is made in Table 3 to compare the conceptual contents of the WHO and OECD performance frameworks with the conceptual contents of a selection of the national frameworks. The table suggests that there are many points of agreement in the various frameworks. For example, all of the frameworks seem to pursue concepts of health outcomes (or 'effectiveness') and various aspects of responsiveness (or 'patient satisfaction' or 'patient experience') at a conceptual level, although alternative terminology abounds. Also, as has been noted already, process and structural domains have often been proposed as proxies for outcome domains. All but one of the frameworks pursue ideas of efficiency although the indicators proposed are usually measures such as unit costs, length of stay and day surgery rates rather than more general measures of efficiency. There are also points of disagreement. For example, neither the Canadian, nor the American frameworks reported on here, include equity goals. It must be noted again, however, that there is incomplete coverage of American initiatives. For example, the American initiative, 'Healthy People 2000', which has not been reviewed in the Annex, has set goals for reducing health disparities among Americans, with particular attention being focused on the relative health of minority groups. Moreover, the Agency for Healthcare Research and Quality has received a congressional mandate recently to produce an annual report on disparities in health care delivery.

\section{KEY INDICATORS OF PERFORMANCE}

21. In this section we review the key indicators of performance collected or proposed for collection in Australia, Canada, the UK and the USA. We have been somewhat selective, and have summarised among the hundreds of measures put forward. We compare these key indicators with those already being collected by the OECD. Finally, we review the prospects for improving the performance indicators collected routinely in OECD Health Data.

\section{Health outcome indicators}

22. The long search for unambiguous and reliable measures of health outcome at a population level, using routine statistics, is proving difficult. By health outcome is meant 'changes in health status brought about by health care - or health system - activities'. That is because under ordinary conditions of health care delivery, it is hard to isolate the impact of health care from the impact of other determinants of health status. Consequently, most, if not all, of the 'health outcome' indicators, being proposed by countries, are, in fact, proxy indicators of outcomes. These proxy indicators are either:

1) health status measures, where there are reasons to suppose that mortality or morbidity should be amenable to appropriate and timely medical care or;

2) process of care measures, which measure utilisation which is believed to correlate highly with good outcomes.

23. Table 4 presents some of the most frequently used 'health outcome' indicators identified in the national frameworks as well as those indicators collected in OECD Health Data and in other OECD projects. $^{3}$

3. It should be noted that countries might collect this data for other purposes at a national level. The checkmark reflects if it was explicitly stated in the performance framework documents as an agreed-upon indicator. 
24. The first 6 indicators, or sets of indicators, listed in the table are all measures of avoidable mortality, morbidity or hospitalisation. The use of 'avoidable' mortality and morbidity entails adopting hypotheses about causation, often based on evidence in the medical literature. The widespread dissemination of the approach by Charlton in 1983 and Rutstein in 1980 and the publications like the European Community Atlas of Avoidable Deaths has raised awareness about the potential of these indicators. However, there is evidence which must cause us to question how well these avoidable mortality and morbidity indicators reflect the impact of health services themselves, as opposed to other factors affecting health. Past research on the international and national levels has found little significant association between avoidable mortality and health care variables, such as expenditure and access (Poikolainen et. al., 1988; Mackenbach, 1991). Stronger associations, however, are found in the literature between infant mortality and health expenditure per capita as well as the number of doctors (Elola et. al., 1995; Grubaugh et. al., 1994). Low birth weight is also used frequently as a performance indicator in countries. Yet the evidence linking low birth weight to the quality of routine prenatal care is controversial, and many other factors may confound the association. (Epstein, 1995; Eddy, 1998).

25. Similar work has been conducted to assess the validity of 'avoidable morbidity' indicators One study analysed the use of admission rates for three conditions - asthma, diabetes, and epilepsy - as an indicator of quality of care (Giuffrida, 1999). These conditions were chosen because they were considered as those for which timely and effective primary care could be expected to reduce the risk of admission to hospital by preventing the onset of illness, controlling an acute episode, or better long term management. The study found that admissions are significantly influenced by factors outside health care system - in particular population characteristics. Based on these findings, the validity of these indicators to be used as a measure of health outcome is uncertain.

26. The next 4 measures in the table are also avoidable mortality measures but they are likely to be more reliable as indicators of outcome because by their nature they are standardised for the incidence of disease or, in the case of perioperative mortality, for the frequency of treatment. Unfortunately, these measures are very demanding of information systems: they depend upon countries either having longitudinal data at the individual level or information systems which allow for linkage across datasets, for instance, between mortality and hospital administrative databases.

27. The UK is using 28-day emergency readmission rates as an indicator of complications. There has been a debate of the advantages and limitations of using hospital readmissions as a measure of the quality of health care. Some experts have stated that a global indicator of (all-cause) readmissions has limited value as it reflects more the progression of disease, than a discrete outcome of care (Gornick, et. al., 1998 and Benbassat, 2000). Benbassat suggests that focusing on readmission rates for specific disorders (e.g., labour and childbirth, $\mathrm{CABG}$ ) might yield more value in terms of highlighting the level of quality of care.

28. The last two indicators listed in the table use process-of-care measures as proxies for outcomes. These measures reflect utilisation that is believed to correlate highly with good outcomes. There has been a debate about the extent to which process measures can be used as valid measures of outcomes. In the past, HEDIS, in the US, has come under scrutiny for relying too heavily on such proxies (Epstein, 1995; Meyer et. al., 1998). However, many believe that process of care measures may be the best way forward in the short term.

29. What is most striking about the list of indicators in Table 4 is how far it falls short of a comprehensive list which would cover all of the health outcomes from a modern system of health care.

30. It can be seen from Table 4 that OECD is already collecting the first 6 indicators or sets of indicators, and the $12^{\text {th }}$, listed in the table. In addition, several of the remaining indicators will be collected by OECD for the countries taking part in the Ageing Related Disease (ARD) Project. That project may form a basis for including these indicators in OECD Health Data in future years. That leaves three indicators: survival rates from dialysis and transplants; 30-day perioperative mortality rates; and 28-day 
emergency readmission rates which are not yet collected by OECD but which are available in one or two of the countries surveyed here. It will be worth enquiring whether these indicators are available in other Member countries, with a view to including them in OECD Health Data in future years.

\section{Responsiveness indicators}

31. Concepts of the responsiveness of health systems to consumers vary widely, embracing ideas of patient satisfaction, patient acceptability and patient experience. The main distinction is between satisfaction and acceptability on the one hand and experience on the other hand. The former will depend on expectations. The latter seeks to describe objective characteristics of health service delivery, such as whether patients were (factually) given a choice of treatment. The distinction between the two can be illustrated from a recent Commonwealth Fund Survey of public discontent with health care in five countries (Donelan et. al., 1999). British respondents were less 'worried' about waiting for non-emergency care than respondents in all but one of the other four countries in the survey, despite reporting much longer waiting times for non-emergency surgery, on average, than respondents in any of the other four countries.

32. The measurement of patient experience is more straightforward than the measurement of health outcome. It is relatively easy to conduct patient surveys or to collect administrative data on patient experience. More important, putting aside difficulties of respondent bias or recall, in the case of experience there will be a one to one relationship between the information collected and the concept specified. The main problem is the expense of sample surveys - especially if they are to yield statistically reliable data down to, say, provider level.

33. Table 5 summarises, selectively, some of the most frequently used or proposed responsiveness indicators which have been addressed in this study.

- WHO intends to collect data for all its Member countries on: patient-rated dignity of treatment; patientrated autonomy and confidentiality; patient-rated promptness of attention; patient-rated quality of basic amenities; patient-related access to support networks during care; and patient-rated choice of care provider.

- OECD is planning to carry out a project on the reasons for variations in waiting times for nonemergency surgery among selected member countries. This may yield enough evidence on such waiting times to allow a table to be added to 'OECD Health Data'.

- In the US, the Agency for Health Care Research and Quality (AHRQ) has granted funds to develop a nation-wide survey entitled, Consumer Assessment of Health Plans (CAHPS). It measures items such as waiting time, continuity of care, access to specialists, and the effectiveness of patient-physician communication. CAPHS is currently being incorporated into the National Committee on Quality Assurance (NCQA) set of HEDIS indicators.

- The UK is now conducting a regular Survey of Patient and User Experience. In the first year the questions concentrated on general practice. In addition, there will be rolling modules to review in more detail patient experiences in selected areas (e.g. hospital care for coronary heart disease patients). The survey covers, among other things: access and waiting times; physician/patient communication; patients' views on the knowledge, courtesy, and the helpfulness of other staff; and information provided at discharge.

- The Picker Institute specialises in conducting surveys measuring patients' experiences. The surveys ask patients to report on "what happened" to them rather than to rate how satisfied they were (Coulter et. al., forthcoming). Picker surveys measure seven dimensions of patient care: respect for patients' 
preferences, co-ordination of care, information and education, physical comfort, emotional support, involvement of family and friends, continuity and transition. A study is forthcoming to discuss the results of surveys conducted in Germany, Sweden, Switzerland, the UK and the USA.

34. An implication of this surge of interest in collecting data on patient satisfaction and experience is that there are prospects for OECD to add further tables on this aspect of performance to 'OECD Health Data', in due course. However, given the signs of proliferation of different measures in this area, there may be a need for further international harmonisation among responsiveness indicators, if the potential for international comparisons is to be fully realised.

\section{Equity indicators}

35. The construction of a full set of equity indicators for a health system is very demanding of data. We have identified perhaps five different dimensions to equity: health, health outcome, access, responsiveness, and finance. In addition, there are many population groups, across which disparities might be monitored, including: age, gender, ethnic group, income and geography. Moreover, access to multiple data sets is often required. For example, the measurement of equity of access requires, across, say, income groups, knowledge of the distribution of health status across those groups. Similarly, the measurement of equity in finance requires knowledge of the distribution of disposable household income.

36. The list of contributions to the measurement of various aspects of the equity of health systems includes the following.

- There is a considerable body of evidence on equity of health status (mortality and morbidity) in different OECD countries suggesting disparities across a variety of population groups.

- The EU has sponsored impressive work on equity of access and equity of finance for a selection of OECD countries (for example, Van Doorslaer et. al., 1993).

- WHO has made judgements of equity of health, equity of responsiveness and equity of finance for its Member countries for the performance comparisons published in the World Health Report 2000.

- Two of the countries in this study, Australia and the UK are monitoring or plan to monitor equity of access. It is not yet clear what measures Australia proposes to collect. Judging by Annex 6, the UK is planning to look only at geographical equity. It is not clear whether there will be adjustment for health variations across geographical areas.

37. The OECD is beginning to collect some data on equity of health status for a selection of Member countries, as part of its work on acquiring information from health interview surveys. As has been mentioned above, there is some international work on the equity of health care financing. However, there seems to be relatively little work extant or planned on equity in access to health services. WHO does not consider equity of access explicitly in its performance framework and only two out of four of the countries surveyed here have expressed the intention to collect such data in their frameworks.

\section{Efficiency indicators}

38. In different ways, WHO and OECD conceptualise high level, general indicators of efficiency or 'performance'. The WHO has actually made estimates of performance for all of its Member countries involving a composite measure of performance, which weights achievements against equity and quality goals in relation to resources. 
39. For the most part, the four OECD Member countries surveyed here are proposing to use lowlevel efficiency indicators in their performance frameworks, such as unit costs, length of stay and ratios of day case surgery to all surgery.

40. However, Annex 6 reports that the UK had an interesting experience in first tracking and then targeting a composite efficiency indicator for hospital services in the 1990s. This indicator consisted of the ratio of: annual changes in cost weighted activity produced by hospitals; to annual changes in real resources used by hospitals. The experience of using this indicator is reported on in the next section.

41. Under its new Performance Assessment Framework, the UK is now proposing to use a more general indicator of hospital performance including: fair access; cost-effectiveness; outcomes of care and responsiveness to patients. It is intended that the cost of providing care in high quality, high performing hospitals will become a benchmark for the remaining hospitals.

42. The OECD has no proposals currently for producing a composite, high level indicator of efficiency for Member countries. Rather, it proposes presenting separate, individual indicators for health outcomes, and responsiveness (alongside existing data on real expenditure) as and when these become available. We note that in principle it would be possible to move on to produce for our Member countries efficiency indicators of the kind proposed by the UK, although gaps in OECD health data preclude that happening in the near future.

\section{ANALYSIS}

\section{What is controllable?}

43. A key issue is how to discriminate between controllable and uncontrollable variations in performance. As we have seen, that arises particularly in the area of health outcome measures, when health status measures are used as proxies for health outcomes. There is likely to be less of a problem with process 'measures' of outcomes or with measures of responsiveness. However, even here it may be require investigation and analysis to identify what levers must be pulled to improve performance. For example, poor quality in the service provided by a department in a globally budgeted public hospital may be due to inefficient working practices (which are the responsibility of local management), shortages of resources (which are the responsibility of the relevant funding body) or inappropriate national wage scales (which are likely to be the responsibility of central government).

\section{Composite indicators}

44. Another issue, which faces all who devise sets of performance indicators, is whether or not to aggregate the indicators to provide composite or summary measures. The main argument in favour of aggregation is that without it, those trying to monitor performance may drown in a sea of detail. The main argument against aggregation is that to the extent indicators reflect performance against different goals, aggregation requires adding 'apples' and 'pears'. Value judgements are required to weight different objectives, unless market prices or average unit costs can be used as weights. Moreover, if only summary indicators are published, the origin of variations in performance tends to be concealed. However, it is possible to publish both summary measures and their components.

45. The approach adopted by WHO in its Health Report 2000 represents one extreme. Efficiency and equity dimensions of performance have all been rolled into one number for each country. OECD is not proposing to embark on such summarisation of performance. Nor do any of the four countries considered here appear to be proposing such aggregation in their performance frameworks. In the case of the UK, 
'spider diagrams' are being used as a visual aid to assist the reader to absorb a variety of indicators, together with their appropriate benchmarks.

\section{Setting benchmarks}

46. A third issue is how to set standards or benchmarks for performance. One possibility - adopted recently by the UK - is to adopt certain ambitious but achievable targets for key areas of care, combined with a 'traffic light' system. The national standards will include targets for key conditions and diseases, waiting times, the quality of care and efficiency. All NHS organisations will be classified as 'green', 'yellow' or 'red' on the basis of their performance. Red organisation will be those failing to meet a number of the core national targets. 'Yellow' organisations will be those meeting all or most national core targets but would not be in the top $25 \%$ of performance. Green organisation will be those meeting all targets and scoring in the top $25 \%$ of organisations on performance, taking account of 'value added'. The benchmarks will be reviewed periodically.

47. Another possibility, demonstrated recently by WHO for Member countries, is to use 'frontier analysis' to identify best performance among the performing units. For example, WHO made use of multivariate statistical analysis to identify the upper and lower limits of health status, observed across countries, after allowing for certain postulated determinants of health status such as health expenditure and levels of education (Evans et. al., 2000).

\section{PERFORMANCE MANAGEMENT}

\section{Types of performance management}

48. Performance management in OECD health systems is a large, diverse and evolving subject, which is dealt with only selectively in this paper. By 'performance management' we mean the whole set of institutional and incentive arrangements by which performance information is (or is not) used to influence performance in health care systems. These institutional arrangements may be somewhat centralised, as in the UK or they may be decentralised, as in the US. They may rely on one or more of a variety of incentives. The list of possibilities includes: professional motivation under an 'agency relationship'; command and control; and self-interested behaviour in a market, or quasi-market, environment.

49. There are some important similarities in performance management arrangements across OECD health systems and there are some important differences. A point of similarity is that all OECD countries have licensing systems, which confer monopolies on certain health care professions. That is usually accompanied by duties of self-regulation of the quality of care by the professions. It is as though an implicit 'contract' has been drawn up between society and the health professions under which the professions are given a monopoly of practice, usually with high rewards and status, in return for undertaking to control the quality of care, to the best of their individual and collective ability. Selfregulation is usually accompanied by formal institutions for peer review. Peer review tends to go on behind closed doors, to a large extent. Society then proceeds to trust the health care professions to deliver their side of the bargain, at least for most of the time. Occasionally, there is felt to be a need to re-negotiate this 'contract' - as has happened recently in the UK following revelations about the failure of 'self regulation' to check quickly enough the activities of a small number of seriously incompetent and errant doctors.

50. The underlying reason for such arrangements is that there is asymmetry of knowledge between health care professionals and patients (and, indeed, between health care professionals and lay managers of health care institutions). It is closely related to the difficulty of finding unambiguous and reliable measures of health outcome - already referred to above. 
51. One of the big questions facing health policy makers is whether to strengthen self-regulation or whether to adopt a mix of self-regulation and external scrutiny. It is almost certainly quite unrealistic to contemplate displacing self-regulation altogether. In some countries, the search for improved outcomes and quality has focused mainly on strengthening the institutions and activities of peer review. There is plenty of scope for that since there is evidence in many, if not all OECD countries, of great variability in clinical practice and of medical errors (Institute of Med. 1999). Strengthening peer review is the route which has been followed in the Netherlands since the late 1970's, with the help of institutions such as the CBO 'Central Support Organisation for Peer Review' (Klazinga et. al., 1998). In other countries, such as the four covered in this paper, there is more emphasis on a joint approach to quality measurement: both on developing self regulation and on publishing some data on quality, with a view to providing external scrutiny of results. For example, in the UK, the publication of various quality indicators for hospitals was introduced with the 'Patients Charter' in the early 1990s. In the US, the National Committee for Quality Assurance has published quality indicators for managed care organisations since the early 1990s. These data were originally aimed at the employers who purchased health insurance for their employees.

52. In other respects, there are wide differences between countries in performance management arrangements. These differences stem from the variety of institutional arrangements governing health care across OECD countries. One dimension of variation is between private and public institutions. Another dimension of variation is between centralised and decentralised arrangements. Yet another dimension of variation is between management-based command and control and market based incentivisation of providers. In the UK, putting aside self-regulation, performance management institutions are public, they are partly centralised and there is a history of the centre using performance indicators to set targets for the local health authorities under its line management. In the US, the relevant organisations are mainly private, the relevant decision-makers are mainly decentralised and the emphasis, at least of central initiatives, has been on providing information to facilitate choice by autonomous consumers and purchasers in the health care market. In Australia and Canada, most of the responsibility for managing health care lies at the State and Provincial levels, respectively, and much of the performance management agenda is being developed at these levels (see Annexes 1 and 4). In these two countries the emphases are on using performance information to hold users of public funds accountable and on benchmarking of performance.

\section{Evaluation of performance management initiatives}

53. There do not appear to have been many evaluations of attempts to use performance indicators and to improve performance management in OECD countries. However, the country summary for the UK (Annex 6) reports that there were repeated annual improvements in the measured productivity of hospital services in the 1980's in England following the introduction of the first set of performance indicators in the NHS and the profound reforms to hospital management which took place after 1983. Furthermore, there was acceleration in the rate of improvement of productivity following the annual targeting of the productivity indicator and the introduction of competitive incentives for hospitals in the 'internal market' reforms in England, which took place in 1991. By 1995, the gain in measured hospital productivity since 1979 had caught up with the gain in measured productivity in the UK economy as a whole since 1979 arguably a notable achievement for a service industry. Annex 6 also reports that by 1996 doubts had set in about such annual targeting. It was felt that there was an increasing risk that quality was being sacrificed in the pursuit of quantity. Also there were growing worries about gaming of the productivity measure itself.

54. The UK has now downplayed competitive incentives for hospitals although the purchaser/provider split remains. It has also introduced a wider concept of hospital efficiency, which will include quality and equity aspects of hospital care, as well as reference costs. New targets will be set using this broader measure and they will be backed up by incentives in the form of 'earned autonomy'. Good performance will be rewarded by greater local management autonomy whereas poor performance will lead to partial loss of local autonomy. 
55. Turning to the US, in recent years, as managed care has gained the upper hand and costs have been squeezed, at least temporarily, the concern has turned increasingly to the perceived threat to the quality of care. Many of the initiatives reviewed in Annex 8 relate to attempts, such as HEDIS, to develop indicators of the quality of health care. These are intended to balance indicators of cost when informing choice of health care plans by consumers or group purchasers. However, it is reported in Annex 8 that most employers in the US are still focusing on costs in their selection of health care plans (Meyer et. al., 1999). In a recent review of published evaluations of seven different quality reporting systems across the US (Marshall et. al., 2000), the authors argue that the expected gains from public disclosure of quality information have not been made clear by the proponents of such disclosure. Moreover, both the benefits and the risks have received minimal empirical investigation.

56. According to Marshall, et. al., the published studies suggest that public disclosure of performance data for hospitals, health care professionals and health care organisations has little effect on the behaviour of consumers or purchasers. Individual physicians are also sceptical, perceiving adverse side effects of disclosure. For example, following the publication of surgeon-specific coronary artery bypass grafting (CABG) mortality rates in Pennsylvania, almost two-thirds of cardiologists reported increasing problems in finding surgeons to operate on high-risk patients. A similar proportion of cardiac surgeons reported that they were less willing to operate on such patients. However, provider organisations, in particular hospitals, seemed to be more responsive to such disclosures. In New York, the CABG mortality rate declined much more steeply than the national average following public disclosure. Hospitals may have withdrawn admitting privileges from low volume, high-risk surgeons. They may also have put pressure on other surgeons to improve their performance. The authors of the literature review concluded that health care performance data is likely to be of most use if it is directed at organisational providers. Similar observations about 'closing the loop' by feeding back performance information directly to providers have been made by Legnini $e t$. al., 2000. The suggestion seems to be that external review will work best if it is used to complement and stimulate peer review.

57. What is the role of international comparisons in performance management? International bodies can collect data to inform international benchmarking of health system performance. They can also try to facilitate the spread of good practice in performance measurement and management. The OECD has long drawn attention to wide variations in health expenditure per capita. These have regularly been quoted in domestic debates about levels of health spending. More recently, comparative international data has begun to emerge on indicators such as 5-year survival following a diagnosis of cancer and waiting times for elective surgery. Again, wide variations have been shown to exist. Moreover, OECD has pointed out that higher health spending appears to be associated with longer cancer survival and shorter waiting times (Anderson et. al., 2000). Data such as these can help to inform decisions on the desired level of health spending. 
DEELSA/ELSA/WD(2000)8

\section{CONCLUSIONS}

58. Three objectives for this paper were set out in paragraph 8, above. The following conclusions may be drawn in relation to each of these objectives.

i. Although there are many points of agreement emerging between international organisations and among Member countries about concepts of performance measurement for health care systems, agreement is still far from complete. That is partly because of differences in the objectives set for health systems in different frameworks, and partly because concessions are made in some frameworks to the difficulties of operationalising high level concepts of outcomes and efficiency.

ii. A selective review of the performance indicators being developed by WHO, OECD and each of four OECD Member countries suggests that the development of indicators is proceeding at different speeds, in different areas of performance measurement. Relatively slow progress is being made in the area of health outcomes. Moreover, such measures as do exist at the population level are invariably proxies for health outcomes. There are signs of faster progress with developing indicators of the responsiveness of health services to consumers, although there may be a need for international harmonisation of measures if comparative work is to proceed at an international level. There is slow progress with the development of equity indicators. There is also slow progress with the compilation of overall measures of the efficiency of health systems of a kind that command confidence. The asymmetry of knowledge between health care professionals, on the one hand, and health care consumers and lay managers, on the other, seems here to stay for some time to come. Nevertheless, given the effort now being put in to collecting performance indicators in many OECD Member countries, there seem to be good prospects for improving coverage of such indicators in $O E C D$ Health Data within the next few years.

iii. There are similarities and differences across OECD countries in performance management institutions, using 'performance management' in a broad sense. All countries rely heavily on professional licensure, self-regulation and peer review for controlling the quality of medical and nursing care. That is not surprising in view of the asymmetry of knowledge referred to above. Apart from that, the institutions of 'external' performance management differ widely between countries. The optimal role for external scrutiny is not yet well defined. Questions remain about who should be the recipients of performance indicators and what incentives there should be to act upon them. The few evaluations we have of the use of performance indicators suggest that publishing indicators of performance in circumstances where there are incentives to act upon them may indeed have a favourable effect on measured performance. There are signs that providers may be more responsive than other actors in the health care system are to such publication. However, publication can also have unintended and unwanted side effects. That is probably an inevitable consequence of the fact that the available measures of health outcomes and responsiveness are frail and incomplete. A possible implication is that 'external' review and peer review should be seen as complementary and used in a climate of co-operation. Meanwhile, it is clear that the searches both for better indicators of the 'quality' of health care, and for a better understanding of what determines the behaviour of the key actors in health systems, should go on. 


\section{REFERENCES}

Alberta Health and Wellness (1999)

Expectations and Measures: Provincial Priorities for the Development of Health and Health System Expectations and Measures.

Alberta Treasury (2000)

Alberta Health 2000-2003 Business Plan.

Anderson, G.F., Hurst, J., Hussey, P.S., and Jee-Hughes, M. (2000)

"Health Spending and Outcomes: Trends in OECD countries, 1960-1998. Do Americans get more from their health care systems for the larger share of wealth they spend on health?" in Health Affairs, May/June 2000, Vol. 19, No. 3.

Australian Health Ministers' Advisory Council (1996)

The final report of the Taskforce on quality in Australian health care, Australian Government Publishing Service, Canberra.

Australian Institute of Health and Welfare (1998) Australia's Health 1998: the sixth biennial health report of the Australian Institute of Health and Welfare, Australian Institute of Health and Welfare, Canberra.

Benbasset, J. and M. Taragin (2000)

Hospital Readmissions as a Measure of Quality of Health Care. Arch Intern Med, Vol. 160, Apr. 24, 2000 .

Blendon, R. et. al. (1995)

Who has the Best Health Care System? A Second Look, Vol. 14, No. 4, 220-230.

Bodenheimer, T. (1999)

The American Health Care System: The Movement for Improved Quality in Health Care, The New England Journal of Medicine, Vol. 340, No. 6, pp. 488-492.

Boyce N, McNeil J, Graves D, Dunt D. (1997), Quality and Outcome Indicators for Acute Healthcare Services, Australian Government Publishing Service, Canberra.

Brennan, T., L. Leape, NM Laird, et. al. (1991) Incidence of Adverse Events and Negligence in Hospitalised Patients: Results of the Harvard Medical Practice Study I. New England Journal of Medicine, 324: 370-376.

Buchan H. (1998),

Different countries, different cultures: convergent or divergent evolution for health care quality?,

British Medical Journal (Quality in Health Care, (Supp), vol 7, pp 62-67.

Canadian Institute of Health Information, (1999),

National Consensus Conference on Population Health Indicators, Final Report.

Canadian Institute of Health Information (2000),

Health Care in Canada 2000: A First Annual Report. 
Canadian Institute of Health Information (2000),

Health Indicators 2000.

Charlton, JR. et. al. (1983),

Geographical variation in mortality from conditions amenable to medical intervention in England and Wales. Lancet, 1: 691-696.

Chassin, M. et. al. (1996),

Benefits and hazards of reporting medical outcomes publicly. N Eng. J. Medicine, 334: 394-398.

Chassin, M., R.W. Galvin, and the National Roundtable on Health Care Quality (1998),

The Urgent Need to Improve Health Care Quality: Institute of Medicine National Roundtable on Health Care Quality, Journal of American Medical Association, Vol. 280, No. 11, 1000-1005.

Collopy, B.T. (1998),

Health care performance measurement systems and the ACHS Care Evaluation Program, J. Quality Clinical Practice, 18, 171-176.

Coulter A. et. al. (forthcoming),

Comparing patient's experiences of hospital care in Germany, Sweden, Switzerland, UK, and the USA.

Darby, M. (1998),

Health care quality: from data to accountability. Academic Medicine, Vol. 73, No. 8, 843-853.

Davis, K. (1999),

International Health Policy: Common Problems, Alternative Strategies. Commentary.

Health Affairs, May/June 99, 135-143.

Donelan K, Blendon RJ, Schoen C, Davis K, Binns K. (1999),

The Cost of Health System Change: Public Discontent in Five Nations, Health Affairs, vol 10, no 29.

Draper M, Hill S. (1996),

The role of patient satisfaction surveys in a national approach to hospital quality management, Australian Government Publishing Service, Canberra.

Eddy, D.M. (1998),

Performance Measurement: Problems and Solutions, Health Affairs, Vol. 17, No. 4, 7-25.

Edgman-Levitan, S. and PD. Cleary (1996),

What information do consumers want and need? Health Affairs. Winter, 15, 42-56.

Elola, J et. al.,. (1995),

Health Indicators and the Organisation of Health Care Systems in Western Europe, in American

Journal of Public Health, Vol. 1985, No. 10, 1397-1405.

Enthoven, A. (2000),

In Pursuit of An Improving British NHS, Health Affairs, Vol. 19, No. 3, 102-119.

Epstein, A. (1995),

Performance Reports on Quality - Prototypes, Problems, and Prospects. The New England Journal of Medicine, Vol. 333, No. 1, pp. 57-61. 


\section{DEELSA/ELSA/WD(2000)8}

Epstein, A. (1998),

Rolling Down the Runway: The Challenges Ahead for Quality Report Cards. Journal of American Medical Association, 279(21): 1691-1696.

Epstein, A. (2000),

Public Release of Performance Data: A Progress Report From the Front. Journal of American Medical Association, 283(14).

Evans, D.B., Tandon, A, Murray, C.J.L., Lauer, J.A. (2000),

The comparative efficiency of national health systems in producing health: an analysis of 191

countries; GPE Discussion Paper Series: No 29, WHO, Geneva.

Fletcher, M. (2000),

The Quality of Australian Health Care: Current Issues and Future Directions, Commonwealth

Department of Health and Aged Care, Occasional Papers: Health Financing Series, Vol. 6.

Garpenby, P. and P. Carlsson (1998),

"Quality Registers in the Swedish Health Service," in Outcome Measuring, Spris forlag, Stockholm, pp. 141-150.

Giuffrida, A. et. al. (1999),

Measuring quality of care with routine data: avoiding confusion between performance indicators and health outcomes, BMJ, Vol. 319, 94-98.

Gornick, et. al. (1991),

US initiatives and approaches for outcomes and effectiveness research, Health Policy, 17: 209-225.

Grout, P. et. al. (2000),

Benchmarking and Incentives in the NHS. Office of Health Economics, London.

Grubaugh et. al. (1994),

Comparing the Performance of health care systems, Southern Economic Journal, Vol. 60, No. 4, pp. 1030-1042.

Hannan, E.L. et. al. (1994), Improving outcomes of coronary bypass surgery in New York State, JAMA, Vol. 271: 761-766.

Hannan E.L. et. al. (1995),

The decline in coronary artery bypass graft surgery mortality in New York State, JAMA, 1995; 273: 209-213.

Hannan, E.L. et. al. (1997),

Public release of cardiac surgery outcomes data in New York, Am Heart J.; 134: 1120-1128.

HCFA, Medicare Hospital Mortality Information (1988),

Vols. I-XIV, Dept. of Health and Human Services. Washington DC 1988.

Health Care Financing Administration (2000), www.hcfa.gov; (Quality of Care Information/Performance Measures).

Holland, W.W. (1993),

European Community Atlas of Avoidable Death, Second edition, Volume Two, Oxford University Press. 
Ibrahim JE, Major JW, Boyce N, McNeil J. (1998),

Pilot Hospital-Wide Clinical Indicators Project: final report, Commonwealth Department of Health and Family Services, AusInfo, Canberra.

Institute of Medicine (1999),

To Err is Human: Building A Safer Health System, Ed. By Kohn, L.T., J.M. Corrigan, and M.S.

Donaldson, Committee on Quality of Health Care in American, National Academy Press,

Washington DC.

International Society of Quality Assurance (1999),

Summary of the Second ISQua meeting on Global Indicators on Patient Care, October.

Jencks, S. (2000),

Clinical Performance Measurement: A Hard Sell. Journal of American Medical Association, Vol. 283, No. 15.

Johantgen, M. et. al. (1998),

Quality indicators using hospital discharge data: state and national applications, Jt Comm J Qual Improv, 24(2): 88-105.

Joint Commission of Accreditation of Health Organisation (2000), www.jcaho.org/perfmeas.

Kazandjian, V., Wood, P, and Lawthers J. (1995),

Balancing Science and Practice in Indicator Development: the Maryland Hospital Association

Quality Indicator (QI) project, International Journal for Quality in Health Care, Vol. 7, No. 1, pp. 39-46.

Klazinga, N., K. Lombarts, and J. van Everdingen (1998),

Quality Management in Medical Specialties: The Use of Channels and Dikes in Improving Health Care in the Netherlands. Journal on Quality Improvement. Vol. 24, No. 5, 240- 250.

Lagersten, S., and G. Andersson, National Health Care Quality Registers in Sweden (1996/1997), Federation of Swedish County Councils and National Board of Health and Welfare, Fourth edition.

Langiano, T., and S.J. Martin (1998),

Quality improvement measures adopted by the Italian National Health Service, International Journal of Artificial Organs, Vol. 21, No. 11, pp. 726-729.

Lawrence, M. and J. Synnerman (2000),

National Health Care Quality Registers in Sweden, 1999. The Federation of Swedish County

Councils and the National Board of Health and Welfare, Stockholm. (ISBN 91-7188-572-2).

Legnini, et. al.,. (2000),

"Where Does Performance Measurement Go From Here?" in Health Affairs May/June 2000, pp. 173-177.

Leatherman S, Sutherland K. (1998),

Evolving quality in the new NHS: policy, process, and pragmatic considerations, British Medical

Journal, Vol 7 (Quality in Health Care Supplement) pp 54-61. 


\section{DEELSA/ELSA/WD(2000)8}

Mackenbach, JP. (1991),

Health care expenditure and mortality from amenable conditions in the European Community, in

Health Policy, Vol. 19, 245-255.

Malchau, H. and P. Herberts (1998),

Prognosis of Total Hip Replacement: Revision and Re-revision rate in THR: A Revision-Risk Study of 148,359 Primary Operations. Scientific Exhibition presented at the $65^{\text {th }}$ Annual Meeting of the American Academy of Orthopaedic Surgeons, March 19-23, 1998, New Orleans.

Marshall, M.N., et. al. (2000),

The Public Release of Performance Data. What do we expect to gain? A review of the literature." in JAMA 2000, Vol. 283, pp. 1866-1874.

Meyer, G.,

Presentation to the Commonwealth Fund International Working Group on Quality Indicators:

Quality Measurement Initiatives in the US Federal Government, Agency for Health Care Policy and Research.

Meyer, J. et. al. (1998),

Theory and reality of value-based purchasing: Lessons from the Pioneers, Agency for Health Care

Quality and Research, publication no. 98-0004.

McColl, A. et. al. (1998),

Performance indicators for primary care groups: an evidence-based approach. BMJ, 1998: 317: 1354-60.

McNeil J. (1999),

Report on Patient Safety Monitoring Systems, Unpublished report, Department of Health and Aged Care.

Mossialos, E. (1997),

Citizen's view on health systems in the 15 Member states of the European Union. Health

Economics, Vol. 6, 109-116.

Murray, C.J.L. and J. Frenk (2000),

"A Framework for Assessing the Performance of Health Systems", in Bulletin of the World Health Organization, Vol. 78, No. 6.

National Committee on Quality Assurance, (2000), www.ncqa.org/pages/policy/hedis.

National Expert Advisory Group on Safety and Quality in Australian Health Care (1999), Implementing Safety and Quality Enhancement in Health Care: National Actions to support quality and safety improvement in Australian health care, Department of Health and Aged Care, Australia.

National Health Service (NHS) (1996/1997),

The Patient's Charter: The NHS Performance National Guide, London, Department of Health.

NHS Executive (1997),

A First Class Service: Quality in the new NHS, London, Department of Health.

NHS Executive (1998),

The New NHS: Modern, Dependable, London, HMSO. 
NHS Executive (1999),

Quality and Performance in the NHS: High Level Performance Indicators.

NHS Executive (1999),

Quality and performance in the NHS: Clinical Indicators, London, Department of Health.

National Health Ministers'Benchmarking Working Group (1996),

First National Report on Health Sector Performance Indicators: public hospitals - the state of play, Commonwealth Department of Health and Aged Care, Australia

National Health Ministers'Benchmarking Working Group (1998),

Second National Report on Health Sector Performance Indicators, Commonwealth Department of Health and Aged Care, Australia.

National Health Ministers' Benchmarking Working Group (1999),

Third National Report on Health Sector Performance Indicators, Commonwealth Department of Health and Aged Care, Australia.

New South Wales Health (1999),

A Framework for Managing the Quality of Health Services in NSW, NSW Health Department, State Health Publication.

New Zealand Ministry of Health (1999),

Health Funding Authority Performance Report, Quarter One, 1999/2000.

New Zealand Ministry of Health (2000),

The New Zealand Health Strategy: Discussion Document.

Nutley, S., Smith, P.C. (1998),

"League tables for performance improvement in health care"J. Health Serv. Res. Policy, Volume 3

Number 1, January.

Ontario Hospital Association (1999),

Measuring the Performance of Ontario Acute Care Hospitals.

Or. Z. (2000),

"Determinants of health outcomes in industrialised countries: A pooled cross-country, time-series analysis", in OECD Economic Studies No. 30, Paris.

Orteveit, J. (1996), Informed Choice? Health Service Quality and Outcome Information for Patients. Health Policy: 37: 75-90.

Palmer, RH, Adams MME. (1993),

Quality Improvement/quality assurance taxonomy: a framework for the conference. In: Grady M., Bernstein, J., Robinson, S., etds. Putting research to work in quality improvement. Washington DC: Agency for Health Care Policy and Research, pub. no. AHCPR 93-0001: 13-37.

Poikolainen K and J. Eskola. (1988),

Health Services Resources and their Relation to Mortality from Causes Amenable to Health Care Interventions: A Cross-National Study. International Journal of Epidemiology, Vol. 17, No. 1, 86-89. 
President's Advisory Commission on Consumer Protection and Quality in the Health Care Industry, (1998), "Quality First: Better Health Care for All Americans." www.hcqualitycommission.gov

Rutstein, D. et. al. (1976),

Measuring the Quality of Medical Care. New England Journal of Medicine, 294: 582-588.

Schneider, E. and AM. Epstein (1996),

Influence of cardiac surgery performance reports on referral practices and access to care, $\mathrm{N}$ Engl $\mathrm{J}$ Med, 1996; 335; 251-263.

Schneider, E. and AM. Epstein (1998),

Use of public performance reports: a survey of patients undergoing cardiac surgery. JAMA, 279: 1638-1642.

Shortell, SM et. al.(forthcoming)

Assessing the impact of continuous quality improvement in clinical practice: what it will take to accelerate progress. Milbank Q.

Sisk, JE. (forthcoming)

Increased competition and the quality of care. Milbank Q.

Thomas, E.J., D.M. Studdert, J.P. Newhouse et. al.,. (1999),

Costs of Medical Injuries in Utah and Colorado, Inquiry 36: 255-264.

Van Doorslaer, E., Wagstaff, A. and Rutten, F. (1993),

Equity in the Finance and Delivery of Health Care: an International Perspective, Commission of the European Communities, Oxford University Press.

WHO (2000),

The World Health Report 2000, Health Systems: Improving Performance, Geneva.

Wilson, R, W. Runciman, R.W. Gibberd, BT Harrison, L. Newby, JD Hamilton (1995), The Quality in Australian Health Care Study, Medical Journal of Australia, 458-471.

Wilson R (1997),

Are we committed to improving the safety of health care?, editorial, Medical Journal of Australia, vol 166, pp 452-453. 
Chart 1

\section{The performance measurement and management cycle}


Table 1. WHO Health System Performance Framework

\begin{tabular}{lcc}
\hline Components for assessment & Average level Distribution \\
\hline Goals & & \\
Responsiveness to expectations & \\
Fairness in financial contribution & \\
\hline
\end{tabular}

Source: Murray, C.J.L. and Frenk, J. (2000)

Table 2. OECD Proposed Health System Performance Framework

\begin{tabular}{lcc}
\hline Health improvement/outcomes (+) & Average level & Distribution \\
Responsiveness and access (+) & $\checkmark$ & \\
Financial contribution/health expenditure (-) & & \\
\cline { 2 - 3 } & Efficiency & Equity \\
\hline
\end{tabular}

Adapted from Murray, C.J.L and Frenk, J. (2000) 
Table 3. Comparison of Concepts of Health System Performance

\begin{tabular}{|c|c|c|c|c|c|c|c|c|c|}
\hline $\begin{array}{l}\text { Dimensions and Subcategories of } \\
\text { Health System Performance }\end{array}$ & $\begin{array}{c}\text { OECD } \\
\text { Proposed } \\
\text { Framework }\end{array}$ & WHO Framework & $\begin{array}{c}\text { Australia's } \\
\text { Proposed } \\
\text { Framework }\end{array}$ & $\begin{array}{c}\text { Australia's } \\
\text { Acute Hospital } \\
\text { Performance } \\
\text { Framework }\end{array}$ & $\begin{array}{c}\text { Canada's } \\
\text { Health System } \\
\text { Performance } \\
\text { Framework }\end{array}$ & $\begin{array}{c}\text { United } \\
\text { Kingdom's } \\
\text { NHS High } \\
\text { Level } \\
\text { Performance } \\
\text { Framework }\end{array}$ & $\begin{array}{l}\text { United States } \\
\text { NCQA HEDIS }\end{array}$ & $\begin{array}{l}\text { United States } \\
\text { JCAHO }\end{array}$ & $\begin{array}{l}\text { United States- } \\
\text { President's } \\
\text { Advisory } \\
\text { Commission } \\
\text { on Quality }\end{array}$ \\
\hline Health Improvement/Outcomes & $\mathrm{X}$ & $\mathrm{X}$ & $\mathrm{X}$ & $\mathrm{X}$ & $\mathrm{X}$ & $\mathrm{X}$ & $\mathrm{X}$ & $\mathrm{X}$ & $\mathrm{X}$ \\
\hline Appropriateness & & & $\mathrm{X}$ & $\mathrm{X}$ & $\mathrm{X}$ & $\mathrm{X}$ & $\mathrm{X}$ & $\mathrm{X}$ & $\mathrm{X}$ \\
\hline Capacity/Competence & & & $\mathrm{X}$ & & $\mathrm{X}$ & & & & \\
\hline Safety & & & $\mathrm{X}$ & $\mathrm{X}$ & $\mathrm{X}$ & & & $\mathrm{X}$ & $\mathrm{X}$ \\
\hline Responsiveness & $\mathrm{X}$ & $\mathrm{X}$ & & & & & & & \\
\hline Patient Satisfaction & & & & $\mathrm{X}$ & & & & & \\
\hline Patient experience/accessibility & & & $\mathrm{X}$ & & $\mathrm{X}$ & $\mathrm{X}$ & $\mathrm{X}$ & $\mathrm{x}$ & $\mathrm{X}$ \\
\hline Acceptability & & & $\mathrm{X}$ & & $\mathrm{X}$ & & & & \\
\hline $\begin{array}{c}\text { Accessibility (in terms of } \\
\text { Timeliness of } \\
\text { Services) }\end{array}$ & & & $\mathrm{X}$ & $\mathrm{X}$ & $\mathrm{X}$ & $\mathrm{X}$ & & $\mathrm{X}$ & \\
\hline Continuity & & & $\mathrm{X}$ & & $\mathrm{X}$ & & & $\mathrm{X}$ & \\
\hline Equity & $\mathrm{X}$ & $\mathrm{X}$ & & & & & & & \\
\hline Equity of Health outcomes & $\mathrm{X}$ & $\mathrm{X}$ & & & & & & & \\
\hline Equity of Access & $\mathrm{X}$ & $\mathrm{X}$ (responsiveness) & $\mathrm{X}$ & $\mathrm{X}$ & & $\mathrm{X}$ & & & \\
\hline Equity of Finance & $\mathrm{X}$ & $\mathrm{X}$ & & & & & & & \\
\hline Efficiency & $\mathrm{X}$ & $\mathrm{X}$ & & & & & & & \\
\hline Macroeconomic efficiency & $\mathrm{X}$ & & & & & & & & \\
\hline Overall micro efficiency & $\mathrm{X}$ & $\mathrm{X}$ & & & & & & & \\
\hline Unit costs, etc. & & & $\mathrm{X}$ & $\mathrm{X}$ & $\mathrm{X}$ & $\mathrm{X}$ & $\mathrm{X}$ & $\mathrm{X}$ & \\
\hline
\end{tabular}


Table 4. Most frequently-used health outcome indicators

\begin{tabular}{|l|c|c|c|c|c|}
\hline Health Outcome Indicators & OECD & Australia & Canada & $\begin{array}{l}\text { United } \\
\text { Kingdom }\end{array}$ & $\begin{array}{l}\text { United } \\
\text { States }\end{array}$ \\
\hline $\begin{array}{l}\text { Avoidable mortality by } \\
\text { selected conditions }\end{array}$ & $\mathrm{X}$ & $\mathrm{X}$ & $\mathrm{X}$ & $\mathrm{X}$ & $\mathrm{X}$ \\
\hline Infant mortality & $\mathrm{X}$ & $\mathrm{X}$ & $\mathrm{X}$ & $\mathrm{X}$ & $\mathrm{X}$ \\
\hline Perinatal mortality & $\mathrm{X}$ & $\mathrm{X}$ & $\mathrm{X}$ & $\mathrm{X}$ & $\mathrm{X}$ \\
\hline Low birthweight & $\mathrm{X}$ & $\mathrm{X}$ & $\mathrm{X}$ & $\mathrm{X}$ & $\mathrm{X}$ \\
\hline $\begin{array}{l}\text { Incidence of infectious } \\
\text { diseases }\end{array}$ & $\mathrm{X}$ & $\mathrm{X}$ & $\mathrm{X}$ & $\mathrm{X}$ & $\mathrm{X}$ \\
\hline $\begin{array}{l}\text { Avoidable hospitalisations } \\
\text { by selected conditions }\end{array}$ & $\mathrm{X}$ & & $\mathrm{X}$ & $\mathrm{X}$ & $\mathrm{X}$ \\
\hline Survival rates from cancer & $\mathrm{ARD}$ & & $\mathrm{X}$ & $\mathrm{X}$ & $\mathrm{X}$ \\
\hline $\begin{array}{l}\text { Survival rates from dialysis } \\
\text { and transplants }\end{array}$ & & & $\mathrm{X}$ & & \\
\hline $\begin{array}{l}\text { Inhospital mortality due to } \\
\text { AMI }\end{array}$ & $\mathrm{ARD}$ & & $\mathrm{X}$ & $\mathrm{X}$ & \\
\hline $\begin{array}{l}\text { 30-day perioperative } \\
\text { mortality data }\end{array}$ & & & $\mathrm{X}$ & $\mathrm{X}$ & $\mathrm{X}$ \\
\hline $\begin{array}{l}\text { 28-day emergency } \\
\text { readmission rates }\end{array}$ & & & & $\mathrm{X}$ & \\
\hline Vaccination rates & $\mathrm{ARD}$ & & & & $\mathrm{X}$ \\
\hline $\begin{array}{l}\text { Breast/cervical cancer } \\
\text { screening }\end{array}$ & & & & & \\
\hline
\end{tabular}


Table 5. Most frequently-used responsiveness indicators

\begin{tabular}{|c|c|c|c|c|c|c|}
\hline Responsiveness indicators & WHO & OECD & Australia & Canada & $\begin{array}{c}\text { United } \\
\text { Kingdom }\end{array}$ & United States \\
\hline $\begin{array}{l}\text { Patient satisfaction or } \\
\text { acceptability (various): }\end{array}$ & & & $\mathrm{X}$ & $\mathrm{X}$ & $\mathrm{X}$ & $\mathrm{X}$ \\
\hline $\begin{array}{l}\text { - patient-rated dignity of } \\
\text { treatment }\end{array}$ & $\mathrm{X}$ & & & & & \\
\hline $\begin{array}{l}\text { - patient-rated autonomy } \\
\text { and confidentiality }\end{array}$ & $\mathrm{X}$ & & & & & \\
\hline $\begin{array}{l}\text { - patient-rated } \\
\text { promptness of attention }\end{array}$ & $\mathrm{X}$ & & & & & \\
\hline $\begin{array}{l}\text { - patient-rated quality of } \\
\text { basic amenities }\end{array}$ & $\mathrm{X}$ & & & & & \\
\hline $\begin{array}{l}\text { - patient-rated access to } \\
\text { support networks during } \\
\text { care }\end{array}$ & $X$ & & & & & \\
\hline $\begin{array}{l}\text { - patient-rated choice of } \\
\text { care provider }\end{array}$ & $\mathrm{X}$ & & & & & \\
\hline \multicolumn{7}{|l|}{ Patient experience: } \\
\hline - continuity (various) & & & $\mathrm{X}$ & $\mathrm{X}$ & & $\mathrm{X}$ \\
\hline $\begin{array}{l}\text { - physician/patient } \\
\text { communication (various) }\end{array}$ & & & & & $\mathrm{X}$ & $\mathrm{X}$ \\
\hline $\begin{array}{l}\text { - provision of information } \\
\text { (various) }\end{array}$ & & & & & $\mathrm{X}$ & $X$ \\
\hline - waiting times (various) & & $\begin{array}{c}\mathrm{X} \\
\text { (waiting times } \\
\text { project) }\end{array}$ & $\mathrm{X}$ & & $\mathrm{X}$ & $\mathrm{X}$ \\
\hline - privacy (various) & & & & & $\mathrm{X}$ & \\
\hline - cancelled operations & & & & & $\mathrm{X}$ & \\
\hline - delayed discharge & & & & & $\mathrm{X}$ & \\
\hline
\end{tabular}




\section{ANNEX 1. COUNTRY SUMMARY FOR AUSTRALIA}

59. Measurement and assessment of performance has been conducted in Australia through the work of several governmental bodies and projects:

- Australian Institute of Health and Welfare (AIHW) and its work on the National Health Priority Areas;

- The National Health Ministers' Benchmarking Working Group (NHMBWG) in collaboration with the Steering Committee for the Review of Commonwealth/State Service and the recently established National Health Performance Committee;

- The Australian Health Care Agreements and the Public Health Outcome Funding Agreements and the work to develop performance indicators for monitoring the major funding agreements between the Commonwealth and States and Territories.

- Australian Council on Health Care Standards (ACHS) in the hospital sector;

- Other national indicator projects related to the Community Health Sector, General Practice, Aboriginal and Torres Strait Islanders, and Allied Health Sector.

- Various projects being implemented on the State and Territorial level.

60. Two main trends are occurring in Australia at this time: first, recent efforts to rationalise the work of the current national groups and processes dealing with the development of a national performance measures and second, a move to extend focus beyond acute care towards population health, mental health, general practice and community health activities and outcomes.

\section{Performance Measurement Activity at the National Level}

61. First, several sets of indicators have been identified through the National Health Priority Areas (mental health (initially focusing on depression), cardiovascular health, diabetes, cancer control and injury prevention and control) and asthma, which are monitoring the incidence of the disease and measuring the improvement of health status. These indicators are reported every two years through the publication, Australia's Health (AIHW). Most of the indicators measure the level of mortality and morbidity as well as risk factors in the population.

62. Following its establishment by the Australian Health Ministers Conference in 1994, the National Health Ministers' Benchmarking Working Group (NHMBWG) - in collaboration with the Steering Committee for the Review of Commonwealth/State Service Provision -- developed a set of indicators and benchmarks designed to provide incentives for improved efficiency, effectiveness, and equity in the acute hospital sector. Since then, the NHMBWG has produced three reports (1996, 1998, and 1999), entitled, "The National Report on Health Sector Performance." It presents data according to a performance framework that incorporates the following dimensions: effectiveness, quality, access, equity, appropriateness, and efficiency (NHMBWG, 1996). Indicators for each dimension are presented in Annex 3. The main focus of these reports has been on reporting comparative data for benchmarking the performance for hospital based acute care services across jurisdictions. 
63. In August 1999, the Australian Health Ministers' Conference endorsed the formation of The National Health Performance Committee (NHPC) to further the work of the Benchmarking Working Group. The National Health Performance Committee's main mission is to develop and maintain a national performance measurement framework for the health care system. In a recent discussion paper, it has presented a proposed framework for performance, modelled much after the initial model of the Canadian Institute of Health Information (CIHI) (Annex 2). The framework currently includes aspects of health status, and determinants of health, as well as health system performance. Within the health system performance component, there are the following dimensions: effectiveness, appropriateness, efficiency, responsiveness, accessibility, safety, continuity, capability and sustainability. Equity is included throughout the framework by asking "Is it the same for everyone" in all tiers. The framework is intended to facilitate performance reporting at a national, state, and local levels. NHPC intends for the framework to be as relevant as possible to the other indicator development work occurring in Australia. Indicator selection for the health system component is still ongoing.

64. Performance arrangements based on selected indicators and targets have been experimented with between States and the Commonwealth. In the mid-1990s, under the Commonwealth and the six States and two Territories agreed under the Medicare Agreements that if certain performance targets were achieved annually by the States and Territories, bonus funding would be available. Performance targets measuring efficiency were initially used (e.g. access to emergency departments, waiting times, and number of DRG weighted discharges). However, the programme experienced problems with implementation. Since then, this programme, now called the Australian Health Care Agreements covering 1998-2003, has set bilateral agreements between the Commonwealth and each of the States and Territories to achieve a strategic plan for quality and work towards a set of indicators to monitor performance. However, these performance-related actions are not tied to any penalties or bonuses based on achievement. The AHCAs are refining the definitions of the indicators to ensure that all jurisdictions will collect comparable standard data. In addition, there are the Public Health Outcome Funding Agreements (PHOFAs), which are another type of funding agreements between the Commonwealth and the States and Territories. These agreements were introduced in 1997/98 as an effort to ensure that the States and Territories are using Commonwealth funds according to agreed objectives and outcomes.

65. Similar work is being conducted at the provider level with the adoption of the General Practice Memorandum of Understanding (MoU) between the Commonwealth and the medical profession (as represented by the Royal Australian College of General Practitioners, the Rural Doctors Association of Australia and the Australian Divisions of General Practice). Under the MoU, the profession and the Government share a commitment to work jointly over the life of the $\mathrm{MoU}$ on quality initiatives. Productivity gains linked to improvements in quality will be shared with and reallocated to general practice through mechanisms agreed between the parties. The Government and the profession will work together to develop a range of quality measures to encourage the implementation and measurement of best practice.

66. There is work being conducted by accreditation bodies and by private health insurers and private hospitals. For instance, the Australian Council of Health Care Standards in conjunction with Medical Colleges and special societies has undertaken the joint development of clinical indicators (18 sets of indicators have been developed to date) designed for reporting through the accreditation process. The majority of public and private hospitals participate in accreditation processes. These clinical indicators, defined as "measures of clinical management and/or outcome of care", are used by both public and private hospitals as part of the ACHS accreditation program. As mentioned above, the quality indicators developed by ACHS, relate to clinicians' and patients' perception that care was of a high standard and resulted in desirable outcomes.

67. A trial of selected indicators was conducted to determine their reliability and validity as national indicators: rate of emergency patient readmission within 28 days; rate of unplanned return to operating room; and rates of hospital-acquired infection (rate of hospital acquired bacteraemia and rates of postoperative wound infection following clean and contaminated surgery). The set of reviewed indicators were 
found to be unsuitable for measurement of the performance of the health care system at a national level through difficulties such as inconsistent interpretation of the data requirements for the indicators and inconsistent data collection methods (Ibrahim et. al., 1998). However, the continued measurement of these data was thought to be worthwhile for local use at individual hospitals.

\section{Performance Measurement Activity at the Subnational Level}

68. Several states and territories have been exploring the development of their own performance measurement systems - with a range of different indicators -- that are relevant to their local management and program reporting requirements. Often, they are developed to respond to reporting needs in the budget process with the federal level. There are also reports that several states and territories have moved toward incorporating standards into their purchase agreements with funded providers. Many of these standards are related to activity, financial performance and efficient; however, more and more agreements are starting to incorporate aspects of health improvement and population health, equity, access, and quality.

69. For instance, the Framework for Managing the Quality of Services in NSW was endorsed by the NSW Minister for Health in February 1999. Under the framework, the term "quality" is defined as a broad concept embracing the full range of performance domains, including quality of clinical services. The Framework identifies six dimensions of quality:

- Safety

- Effectiveness

- Efficiency

- Appropriateness

- Consumer participation

- Access

70. The framework proposed the development of a quality of care indicator set to be implemented over three years. A steering committee has been established to finalise the indicator set, and the Health Services Research Group from the University of Newcastle has been engaged to assist in this process. Implementation of the framework is in its early stages. The plan is to devolve responsibility to the Area Health Service Boards and management that they have a responsibility for the quality of care delivered by the service and that this accountability is shared with the clinicians providing the care. Primary emphasis is on strategies and tools to implement this on the provider level effectively.

71. To date, NSW plans to use information collected on performance for public reporting and benchmarking. Reporting is aimed at their Parliament, NSW Treasury, as well as is part of the requirements for the Commonwealth Agreements, such as AHCA and the Public Health Outcomes Funding Agreements. Additionally, there have been established two-year performance agreements for each Area Health Service to be reviewed every six months and annually. In addition to these processes, performance information is made available publicly through two main reports, the Report of the Chief Health Officer http://health.nsw.gov.au/public-health/chorep/chorep.html and the NSW Public Hospitals Comparison Data Book http://health.nsw.gov.au/iasd/iad/yb9798/.

72. Primarily, performance of health services is reported through the NSW Public Hospitals Comparison Data Book (to be renamed the NSW Health Services Comparison Data Book). This report provides detailed information for each public hospital in NSW. Data presented includes details of:

- patient activity, including casemix weighted activity, and non-inpatient activity

- appropriateness 
- efficiency (for example same day surgery rates, average length of stay, relative stay index, cost per casemix weighted inpatient, cost per outpatient occasion of service)

- waiting times for elective surgery and emergency departments

- expenditures

- staffing.

73. The report is being enhanced to provide information within the domains of the Framework for Managing the Quality of Services in NSW (1999), and also to provide an analysis of services delivered and funding provided for each of the regions (Area Health Services) of NSW.

74. Another example of performance measurement, evaluation, and management is in Victoria where the Victorian Department of Human Services is developing its annual Hospital Comparative Data report. The data will mainly focus on efficiency and financial viability. However, Victoria has also been developing indicators around the concept of quality in the following areas: access to care, acceptability of care, appropriateness, effectiveness and safety, continuity of care, and organisational effectiveness of care. It is intended to commission work on the best ways to report on quality of care to different interested groups and to the public. Victoria is already linking some of the indicators under access to care and continuity of care to bonuses for high performing hospitals. 


\section{ANNEX 2. AUSTRALIA'S NATIONAL HEALTH PERFORMANCE COMMITTEE'S FRAMEWORK}

\section{Health Status and Outcomes}

How healthy are Australians? Is it the same for everyone? Where is the most opportunity for improvement?

\begin{tabular}{|c|c|c|c|}
\hline Health Conditions & Human Function & $\begin{array}{l}\text { Life Expectancy and Well- } \\
\text { Being }\end{array}$ & Deaths \\
\hline $\begin{array}{l}\text { Prevalence of disease, } \\
\text { disorder, injury or trauma } \\
\text { or other health-related } \\
\text { states. }\end{array}$ & $\begin{array}{l}\text { Alterations to body, structure } \\
\text { or function (impairment), } \\
\text { activities (activity limitation) } \\
\text { and participation (restrictions } \\
\text { in participation). }\end{array}$ & $\begin{array}{l}\text { Broad measures of physical, } \\
\text { mental, and social well- } \\
\text { being of individuals and } \\
\text { other derived indicators } \\
\text { such as Disability Adjusted } \\
\text { Life Expectancy (DALE). }\end{array}$ & $\begin{array}{l}\text { Age or condition specific } \\
\text { mortality rates. }\end{array}$ \\
\hline
\end{tabular}

\section{Determinants of Health}

Are the factors determining health changing for the better? Is it the same for everyone? Where and for whom are they changing for the worse?

\begin{tabular}{|c|c|c|c|c|c|c|}
\hline Environmental Factors & \multicolumn{2}{|c|}{$\begin{array}{l}\text { Socio-economic } \\
\text { Factors }\end{array}$} & $\begin{array}{l}\text { Community } \\
\text { Capacity }\end{array}$ & \multicolumn{2}{|c|}{ Health Behaviours } & $\begin{array}{l}\text { Person-related } \\
\text { Factors }\end{array}$ \\
\hline $\begin{array}{l}\text { Physical, chemical and } \\
\text { biological factors such as } \\
\text { air, water, food and soil } \\
\text { quality resulting from } \\
\text { chemical pollution and } \\
\text { waste disposal. }\end{array}$ & \multicolumn{2}{|c|}{$\begin{array}{l}\text { Socio-economic factors } \\
\text { such as education, } \\
\text { employment per } \\
\text { capita expenditure on } \\
\text { health, and average } \\
\text { weekly earnings. }\end{array}$} & $\begin{array}{l}\text { Characteristics } \\
\text { of the } \\
\text { community such } \\
\text { as population } \\
\text { density, age } \\
\text { distribution, } \\
\text { health literacy, } \\
\text { housing, } \\
\text { community } \\
\text { support services } \\
\text { and transport. }\end{array}$ & \multicolumn{2}{|c|}{$\begin{array}{l}\text { Attitudes, beliefs } \\
\text { knowledge and } \\
\text { behaviours eg } \\
\text { patterns of eating, } \\
\text { physical activity, } \\
\text { excess alcohol } \\
\text { consumption and } \\
\text { smoking. }\end{array}$} & $\begin{array}{l}\text { Genetic related } \\
\text { susceptibility to } \\
\text { disease and other } \\
\text { factors such as blood } \\
\text { pressure, cholesterol } \\
\text { levels and body } \\
\text { weight. }\end{array}$ \\
\hline \multicolumn{7}{|c|}{ Health System Performance } \\
\hline \multicolumn{7}{|c|}{$\begin{array}{c}\text { How well is the health system performing in delivering quality health actions to improve the health of all } \\
\text { Australians? Is it the same for everyone? }\end{array}$} \\
\hline \multicolumn{2}{|l|}{ Effective } & \multicolumn{3}{|c|}{ Appropriate } & \multicolumn{2}{|r|}{ Efficient } \\
\hline \multicolumn{2}{|c|}{$\begin{array}{l}\text { Care, intervention or action achieves } \\
\text { desired outcome. }\end{array}$} & \multicolumn{3}{|c|}{$\begin{array}{l}\text { Care/intervention/action provided is } \\
\text { relevant to the client's needs and } \\
\text { based on established standards. }\end{array}$} & \multicolumn{2}{|c|}{$\begin{array}{l}\text { Achieving desired results with most } \\
\text { cost effective use of resources. }\end{array}$} \\
\hline \multicolumn{2}{|l|}{ Responsive } & \multicolumn{3}{|c|}{ Accessible } & \multicolumn{2}{|r|}{ Safe } \\
\hline \multicolumn{2}{|c|}{$\begin{array}{l}\text { Service provides respect for persons } \\
\text { and is client orientated: - respect for } \\
\text { dignity, confidential, participate in } \\
\text { choices, prompt, quality of amenities, } \\
\text { access to social support networks, and } \\
\text { choice of provider. }\end{array}$} & \multicolumn{3}{|c|}{$\begin{array}{l}\text { Ability of people to obtain health care } \\
\text { at the right place and right time } \\
\text { irrespective of income, geography and } \\
\text { cultural background. }\end{array}$} & \multicolumn{2}{|c|}{$\begin{array}{l}\text { Potential risks of an intervention or } \\
\text { the environment are identified and } \\
\text { avoided or minimised. }\end{array}$} \\
\hline \multicolumn{2}{|l|}{ Continuous } & \multicolumn{3}{|c|}{ Capable } & \multicolumn{2}{|c|}{ Sustainable } \\
\hline \multicolumn{2}{|c|}{$\begin{array}{l}\text { Ability to provide uninterrupted, } \\
\text { coordinated care or service across } \\
\text { programs, practitioners, organisations } \\
\text { and levels over time. }\end{array}$} & \multicolumn{3}{|c|}{$\begin{array}{l}\text { An individual or service's capacity to } \\
\text { provide a health service based on skills } \\
\text { and knowledge. }\end{array}$} & \multicolumn{2}{|c|}{$\begin{array}{l}\text { System or organisation's capacity to } \\
\text { provide infrastructure such as } \\
\text { workforce, facilities and equipment, } \\
\text { and be innovative and respond to } \\
\text { emerging needs (research, } \\
\text { monitoring). }\end{array}$} \\
\hline
\end{tabular}




\section{ANNEX 3. AUSTRALIA'S ACUTE HOSPITAL PERFORMANCE FRAMEWORK}

\section{Effectiveness}

- Quality

- Hospital Service Outcomes (indicators to be developed and announced)

- Patient Satisfaction : patient satisfaction surveys

- Hospital misadventures: Emergency patient readmission rate; Unplanned return to theatre; Hospitalacquired infection rate.

- Processes: Proportion of facilities that were accredited by the Australian Council on Healthcare Standards; Condition of Capital.

- Appropriateness

- Separations per 1,000 population

- Variations in intervention rates

- Accessibility and Equity

- Queuing: outpatient waiting times; waiting times for elective surgery; emergency department waiting times.

- Equity of Access: (indicators to be developed and announced)

- Physical Access: (indicators to be developed and announced)

\section{Efficiency}

- Cost per casemix-adjusted separation

- Labour cost per casemix-adjusted separation

- User cost of capital per casemix-adjusted separation

- Average length of stay

- Cost per non-admitted occasion of care

Source: The National Health Ministers' Benchmarking Work Group, 1999. 


\section{ANNEX 4. COUNTRY SUMMARY FOR CANADA}

75. In Canada, there has been a variety of work directed at monitoring performance on all levels - at the national, provincial, and hospital levels. National efforts to develop performance indicators are in early stages in Canada; while the majority of work in this area to date is occurring on the provincial level. Examples on provincial level range from either monitoring the achievements of the Ministry of Health or assessing the progress made by newly-created regional health authorities emerging in several provinces. In certain provinces, there have also been some efforts to monitor hospital performance.

76. The trend to monitor performance has originated from an increased emphasis on greater accountability at all levels in Canada. In February 1999, a Social Union Framework Agreement was signed by all first ministers, with the exception of the Premier of Quebec, providing a collaborative framework for social policy in Canada. In this agreement, governments reaffirmed their commitment to respect the principles of Medicare, and recognised the importance of being accountable to Canadians for the health system, including measuring performance on both the performance of the system and the health of Canadians. The combination of this and the provincial and territorial premiers written reassurance to the Prime Minister that new federal transfers for health would be used for health care, and the health ministers workplan adopted in September 1998, will ensure that governments are accountable and deliver quality health services.

77. In order to create effective accountability structures, a significant amount of information will be needed to understand what is being attained by the health care system in Canada and its provinces. This realisation has fostered new programmes to improve information systems in parallel with developing the necessary performance indicators.

\section{Performance Measurement Activity at the National Level}

78. In 1998, on the national level, the Advisory Council on Health Information Structure, Canadian Information Health Institute (CIHI) and Statistics Canada brought together over 500 people from various stakeholder groups to discuss health information needs. In response to this meeting, CIHI and Statistics Canada began a joint effort to identify indicators to report on the health of Canadians and the status of the health care system. In April 2000, a report entitled, "Health Care in Canada 2000: A First Annual Report," was released, with an accompanying document, "Health Indicators 2000." (CIHI, 2000).

79. "Health Indicators 2000" covers a full range of measures based on a proposed framework. The framework is categorised as health status, non-medical determinants of health; health system performance; and community and health system characteristics and it will likely evolve based on comments from various consultations with provinces and regions where priorities and gaps in the current framework will be addressed. Additionally, the framework will evolve to reflect new national accreditation standards.

80. The 1999 version of the model is skewed toward measures of population health and health outcomes. Measures of health system performance require substantial development - for example there is no information on costs captured other than per capita expenditure on public and private sector services and health service outputs and outcomes for hospitals, general practice and community care are poorly described. 
81. The core indicator set is primarily designed to "assist regional health authorities to monitor progress in improving and maintaining the health of the population and the functioning of the health system and ... to assist with reporting to governing bodies, the public and health professional groups." (CIHI) It is intended to reflect agreed national health goals and strategic directions and agreed benchmarks, guidelines and standards.

82. The current section devoted to "health system performance" builds upon the work of the accreditation body, the Canadian Council of Health Services Accreditation (CCHSA) and input from the National Consensus Conference on Population Health Indicators in May 1999. In "Health Indicators 2000," indicators are presented in the category of health system performance. These indicators that were included are those that are currently available at a sub-provincial level across the country and which we were able to be validated with the regions. Through consultation with various stakeholders, additional indicators have been identified and there are plans to present a joint data release with Statistics Canada due out in Fall 2000.

83. Using the CCHSA previous work, there are plans to develop a broad range of data on performance based on the following dimensions, which would cover the entire continuum of health care (Annex 5). Annex 5 also outlines the definition of each dimension, existing data and areas for further development.

84. According to CIHI, indicators will be used in a number of different ways by a variety of different audiences. For example, several regions are already working with their boards and medical staff to address identified areas of divergence from national norms. They have also been used to inform the public on the health care being delivered in different regions of the country via various magazines. In addition, there are plans to work with the Canadian Council on Health Services Accreditation and others to incorporate the indicators into existing management processes at all levels. In general, these indicators for health system performance will be monitored via standardised reporting at both provincial and sub-provincial levels.

85. As mentioned above, much of the national activity is built upon the previous and current work of the Canadian Council on Health Services Accreditation (CCHSA). CCHSA has introduced the programme, the Client-Centred Accreditation in 1995, where principles of quality improvement were incorporated into accreditation standards. As part of this programme, health service organisations were encouraged to develop performance indicators as part of their efforts to improve quality. Since the inception of this programme, CCHSA has worked in collaboration with CIHI to validate indicators to be considered in the accreditation of hospitals. Many of these indicators have turned out to be more "intermediate outcomes" in that they measure the patient's immediate response to a specific episode of care and service and may not necessarily reflect the ultimate outcome for the patients. There has also been a tendency among hospitals to depend upon indicators for processes that are closely linked to the desired outcomes.

86. In more recent years, CCHSA has implemented a project entitled, The AIM Project: Achieving Improved Measurement, which will update the accreditation process in the year 2000. One of the main objectives of the AIM project is to develop standardised performance indicators based on four quality dimensions: responsiveness; system competency; client/community focus; and work life.

87. Each indicator will be linked to a standard and a quality dimension. For example, the indicator, "waiting times" pertains to the standard: the defined population, service providers, and referring organisations can access the organisation's services and to the quality dimension: responsiveness. These indicators will be used on a voluntary basis across accredited organisations. The revised accreditation program will focus on how well organisations use the indicator data to understand and improve their processes and outcomes rather than use the indicator data to assess the organisation's performance at this stage. 
88. As part of its work, CCHSA has also conducted a national, 2-year study to assess the reliability and usefulness of a set of six generic acute care indicators in organisations across Canada. It will seek to identify indicators that can be used to compare organisational performance over time. The six generic acute care indicators are : percent of alternate level of care days; percent of unplanned readmissions to the same hospital with the same or related diagnosis within 7 days; percent of cases classified as may not require hospitalisation; percent of surgical cases that are day surgery; percent of days over/under the expected length of stay (LOS); average length of stay in the emergency department for patients designated as admitted to the hospital.

\section{Performance Measurement at the Provincial Level}

89. In addition, many provincial governments have sought to monitor the performance of their Ministries, asking each Ministry to prepare an annual report of their activities, achievements, and plans for the future. Included in many of these reports from the Ministries of Health are key performance measures to assess how well health needs are being met and how efficient and effective are the health services being delivered in the province. (see below).

90. For instance, in Alberta, the Ministry of Health and Wellness has produced its health and wellness business plan 2000-2003, which outlines four main goals:

1) to deliver of accessible, effective, and high quality health services;

2) to improve health;

3) to support and promote a system for health and;

4) to optimise the effectiveness of the Ministry.

91. The Ministry's business plan is intended to provide direction to the seventeen regional health authorities and two provincial health authorities in preparing their own plans and setting their goals.

92. For each goal, performance indicators are identified. Most of the performance indicators are based on Albertans or health care stakeholders' perceptions (i.e. quality of care received'), heavily relying upon survey data. Based on the first goal, there have been five indicators outlined:

- rating of ease of access to health services (percent of Albertans who report access to health services as "easy" or "very easy;"

- ratings of quality of care received,

- effects of care on health (percent who report that quality of care personally received is "excellent" or "good" and percent who report that the effect of care on their health is "excellent" or "good");

- number of persons waiting for MRI, joint replacement, heart surgery or long term care at the end of each quarter; and

- alternative level of care days.

93. For the second goal, four performance indicators have been identified:

- low birthweight babies;

- mortality rates for injury and suicide;

- breast cancer screening rates;

- childhood immunisation rates. 
94. The third goal has three performance measures:

- percent of Albertans who rate their knowledge of health services available to them as excellent and good;

- percent of Albertans who rate the health system as excellent and good;

- quality of health system information (ratings of Ministry stakeholders ratings of the quality of health system information and information management).

95. Finally, the fourth goal is measured by Ministry stakeholder ratings of the quality of services provided by Alberta Health and Wellness and client ratings of quality of service received by registry and client information service.

96. For instance, in Ontario, since 1997, each Ministry produces an annual business plan outlining its commitments and measurable targets in an effort to inform its taxpayers of the inputs and outputs of the health care system. In its latest 1999-2000 plan, the Ministry of Health has stated in its list of 1999-2000 commitments: to achieve "increased effectiveness and efficiency of the system through performance monitoring and "results-based" decision-making with particular emphasis on benchmarking, external reviews, and expert panels. In addition, in the 1997-1998 business plan, the Ministry of Health proposed a series of key performance measures based on health outcomes, which reflect each of the four core business lines (Table 1).

\section{Table 1. Key Performance Measures for Ontario}

1. Community services to preserve and protect health of citizens;

- Infant mortality rate

- Life expectancy at birth;

- Potential years of life lost from cancer and heart disease;

- Low birth weight rate;

- Number of high risk families receiving home visiting services and/or linked with other appropriate services;

- Number of supportive housing units made available for emergency hostel users;

- Percentage of Ontarians over 75 living in the community.

2. Professional services providing access to primary and specialist care;

- Number of physicians, including specialists per capita

- Number of primary care sites where reform is implemented

- Percentage of target patient enrolment rate achieved

- Number of primary care physicians joining primary care reform

- Availability of general practice doctors and specialists province-wide and in under-serviced areas

- Number of Nursing Task Force Recommendations implemented 
3. Institutional services providing acute and long-term institutional care;

- Percentage of days spent by patients in an acute care hospital when another type of facility would be more appropriate;

- Number of beds available in long term care facilities.

4. Policy and planning developing direction for health care and monitoring quality and performance.

- Ratings of quality and access to health services received from a hospital satisfaction survey.

- Percentage of referrals for investigation and to review committees.

- Number of fraud investigations undertaken.

97. These measures tend to be macro in nature rather than specific targets that could be directly attributed to the commitments made by the Ministry.

98. The University of Toronto and the Ontario Hospital Association (OHA) have produced two reports measuring the performance of Ontario acute care hospitals since 1998. The most recent report, Hospital Report '99 builds on the work that completed in 1998 focusing on system-level performance of hospitals, by delving into more hospital specific information. (OHA, 1999). The 1999 report presents data in four key areas of activity from hospitals which voluntarily chose to participate ${ }^{4}$ : Clinical Utilisation and Outcomes; Financial Performance and Condition; Patient Satisfaction; and System Integration and Change. A total of 38 indicators were selected across the categories based on soundness, relevance, and feasibility. The 2001 report is expected to improve upon common standards used in hospital reporting, thus building the potential for bench marking within Ontario's hospital system; it will also include data on emergency services, complex continuing care and teaching/research.

99. Under Clinical Utilisation and Outcomes, ten common patient groups were identified along with indicators as follows: acute myocardial infarction (AMI); asthma, gastrointestinal hemorrhage (GI bleed); heart failure; community-acquired pneumonia; stroke; carpal tunnel release surgery; prostatectomy; cholecystectomy; and hysterectomy. Assessments of system-level performance are based on 5 indicators of access to technology, 8 indicators of clinical efficiency, and 18 outcome indicators; while the hospitalspecific assessment focus on a subset of these indicators. Under Financial Performance and Condition, indicators were selected for five areas: financial viability, efficiency, liquidity, capital and human resources. For patient satisfaction, more than 50,000 patients were surveyed about their most recent stay at the hospital in the Ontario Hospital Inpatient Survey. General overall satisfaction was covered along with ratings for specific areas such as admissions, nursing, physicians, communication, discharge etc. In terms of the system integration section, indicators were included which reflected increased use of information to improve services, better coordination of care, and higher levels of integration across hospitals and community programmes. Though there have been certain criticisms about the report card's validity, it is an initial step and there are plans to expand the coverage of these so-called "score cards to outpatient acute care services, rehabilitation, and mental health services as well as complex continuing care.

100. In New Brunswick, the Ministry of Health and Wellness has proposed that it should develop, in addition to its overall health status measures, a set of system goals, objectives and performance indicators that will provide a clear direction to those responsible for program delivery. Two types of indicators have been suggested:

4. In 1999, 100 percent of teaching hospitals; $84 \%$ of community hospitals; and $32 \%$ of small hospitals participated - totalling 89 hospitals across the province and covering 91 percent of all patients who received acute care or day surgery care. 
1) population-based indicators that deal with the whole community (e.g. vaccine preventable illness rates, hospitalisation rates for people with chronic illness; and deaths from specific conditions).

2) provider-based health care indicators that related to the performance of specific individuals or institutions (e.g. death rates for hospitals, and the provision of key preventive measures).

The newly established boards for the RHAs are mandated to collect this information and make it available to the Ministry for monitoring.

101. Additionally, the Ministry has initiated effort to monitor its own performance. Ten performance indicators have been identified and reported in the annual report: entitled, Performance Measurement 1999-2000: Supplement to the Main Estimates. These indicators include: life expectancy at birth; infant mortality rate; self-rated health status; percentage of child protection cases where the goals have been met within two years; incidence of communicable diseases; teenage pregnancy rates; average annual agestandardised mortality rates; mortality rate for breast cancer in women; and patient days of hospitalisation in psychiatric hospitals and units.

102. Moreover, a 14-member Premier's Health Quality Council was formed in January 2000 to initiate renewal of New Brunswick's health care system for New Brunswick families. Specifically, the council will work with the government to: - Develop an action plan to move to a health governance system of regional health authorities
and regional health boards.

- $\quad$ Oversee the development and implementation of a new Health Care Report Card, health quality standards, and performance measures.

- $\quad$ Assist in the development of a new Patient Charter of Rights and Responsibilities.

- $\quad$ Provide advice on implementing the recommendations of the Health Services Review report.

103. In the other provinces, there is much activity around the development of "health" indicators, mainly to monitor on the provincial level - specifically aimed at measuring population health status and non-medical determinants of health. However, concentration on the "performance of health care system" indicators as defined in this report is in its early stages.

104. In British Columbia, for instance, work has been ongoing to develop provincial health indicators which are aligned with specific health goals. Overall indicators used for health goals are: life expectancy at birth; disability-free life expectancy, low birthweight rate; infant mortality rate, age-standardised mortality rate, PYLL, self-rated health status, and the human development index as developed by the United Nations. These indicators can be found in the Ministry of Health's annual report, Health Goals for British Columbia. In addition, data are published on waiting times for: hip and knee replacements; nonemergency cardiac surgery; cataracts; corneal transplants; cancer radiation; etc.

- Also, in Manitoba, there has been work to develop a set of indicators to assist the Regional Health Authorities (RHA) in tracking the health status of their populations over time. The current list of indicators has been divided up into two major categories: health status and determinants of health. The 39 indicators are monitored and presented in the Report on the Health of Manitobans, by Manitoba Health.

- In Nova Scotia, there have been efforts by the Department of Health - now overseeing the work of the newly created regional health boards, to develop indicators and targets focused on monitoring health status, health care services, and sustainability. There are 24 indicators including PYLL from selected 
causes, number of teen pregnancies per 1,000 females under 20, self-reported health status, perinatal mortality rate, low birthweight rate, percentage at risk for developing clinical depression, breastfeeding initiation rates, percentage of women overall who smoke in pregnancy, influenza vaccination coverage, cases of hepatitis B infections in infants and children, percentage population with healthy weight range, percentage of Grade 12 students who are smokers, adult smoking rate, survival rates for out-ofhospital cardiac arrests; hospital readmission rates; percentage screened in gynecological screening programme; day surgery as a percentage of all surgeries; elective surgery performed on the same day as hospital admission; mental health clients served on an ambulatory basis; and mental health inpatient days.

- In Saskatchewan, a similar trend is occurring with its new health district boards who are now accountable for the overall health of their district's residents. All health districts will incorporate a health status report into their annual reports. However, there is wide variability in the types of indicators reported by the districts. The established Information Needs Working Groups is currently developing standardised indicators for wide use comparative purposes and the Department of Health has developed a conceptual framework with combines indicators measuring inputs, processes, patient and provider satisfaction and outputs, and outcomes. So far, the Information Needs Working Group has proposed indicators related to prenatal care, infant mortality, high risk birth weight, duration of breast feeding, infant morbidity, teen pregnancy rate, vaccine preventable disease rates, etc. In addition, the Health Services Utilisation and Research Commission has published a study entitled "System Performance Indicators: Toward a Goal-Based Health System" in which they propose indicators that are system-wide, outcome focused, and intrinsic to the mission and long-term goals of the health system. 
ANNEX 5. CANADIAN INSTITUTE FOR HEALTH INFORMATION'S PERFORMANCE FRAMEWORK

\begin{tabular}{|c|c|c|c|}
\hline \multicolumn{4}{|c|}{ Health Status } \\
\hline Health Conditions & Human Function & Well-Being & Deaths \\
\hline $\begin{array}{l}\text { Alterations of health status, } \\
\text { which may be a disease, } \\
\text { disorder, injury or trauma, or } \\
\text { reflect other health-related } \\
\text { states }\end{array}$ & $\begin{array}{l}\text { Alterations to body } \\
\text { functions/structures } \\
\text { (impairment), activities } \\
\text { (activity limitation), and } \\
\text { participation (restrictions in } \\
\text { participation) }\end{array}$ & $\begin{array}{l}\text { Broad measures of } \\
\text { physical/mental/social well- } \\
\text { being of individuals }\end{array}$ & $\begin{array}{l}\text { Age or condition-specific } \\
\text { mortality rates and other } \\
\text { derived indicators }\end{array}$ \\
\hline \multicolumn{4}{|c|}{ Non-Medical Determinants of Health } \\
\hline Health Behaviours & $\begin{array}{l}\text { Living and Working } \\
\text { Conditions }\end{array}$ & Personal Resources & Environmental Factors \\
\hline $\begin{array}{l}\text { Aspects of personal behaviour } \\
\text { and risk factors that influence } \\
\text { health status }\end{array}$ & $\begin{array}{l}\text { Socio-economic } \\
\text { characteristics and working } \\
\text { conditions of population that } \\
\text { are related to health }\end{array}$ & $\begin{array}{l}\text { Measures the prevalence of } \\
\text { factors, such as social support } \\
\text { and life stress, that are related } \\
\text { to health }\end{array}$ & $\begin{array}{l}\text { Environmental factors that } \\
\text { can influence health }\end{array}$ \\
\hline \multicolumn{4}{|c|}{ Health System Performance } \\
\hline Acceptability & Accessibility & Appropriateness & Competence \\
\hline $\begin{array}{l}\text { Care/service provided meets } \\
\text { expectations of client, } \\
\text { community, providers and } \\
\text { paying organisations }\end{array}$ & $\begin{array}{l}\text { Ability of clients/patients to } \\
\text { obtain care/service at the right } \\
\text { place and right time, based on } \\
\text { needs }\end{array}$ & $\begin{array}{l}\text { Care/service provided is } \\
\text { relevant to client/patient needs } \\
\text { and based on established } \\
\text { standards }\end{array}$ & $\begin{array}{l}\text { Individual's knowledge/skills } \\
\text { are appropriate to care/service } \\
\text { provided }\end{array}$ \\
\hline Continuity & Effectiveness & Efficiency & Safety \\
\hline $\begin{array}{l}\text { Ability to provide } \\
\text { uninterrupted, coordinated } \\
\text { care/service across programs, } \\
\text { practitioners, organisations, } \\
\text { and levels of care/service, } \\
\text { over time }\end{array}$ & $\begin{array}{l}\text { Care/service, intervention or } \\
\text { action achieves desired results }\end{array}$ & $\begin{array}{l}\text { Achieving desired results with } \\
\text { most cost-effective use of } \\
\text { resources }\end{array}$ & $\begin{array}{l}\text { Potential risks of an } \\
\text { intervention or the } \\
\text { environment are avoided or } \\
\text { minimized }\end{array}$ \\
\hline \multicolumn{4}{|c|}{ Community and Health System Characteristics } \\
\hline
\end{tabular}




\section{Cont. Annex 5. Canadian Institute for Health Information's Performance Framework: Examples of Existing Measures of Health System Performance}

\begin{tabular}{|c|c|}
\hline $\begin{array}{l}\text { Dimension of Health } \\
\text { System Performance }\end{array}$ & Existing Measures \\
\hline $\begin{array}{l}\text { Acceptability } \\
\text { How well the health system } \\
\text { is meeting our expectations }\end{array}$ & $\begin{array}{l}\text { - Periodic polls of providers and the public about overall satisfaction } \\
\text { with the health system } \\
\text { - Local hospital and other patient satisfaction surveys }\end{array}$ \\
\hline $\begin{array}{l}\text { Accessibility } \\
\text { Whether or not we can } \\
\text { obtain the services we need } \\
\text { at the right place and time }\end{array}$ & $\begin{array}{l}\text { - Use of prevention services (e.g., pap smears and flu shots) by } \\
\text { province } \\
\text { - Studies on who has access to particular types of care } \\
\text { - } \quad \text { Local/provincial waiting time data } \\
\text { - Average distance travelled to hospital }\end{array}$ \\
\hline $\begin{array}{l}\text { Appropriateness } \\
\text { Whether care is relevant to } \\
\text { our needs and is based on } \\
\text { established standards }\end{array}$ & $\begin{array}{l}\text { - How often mothers receive caesarean sections and vaginal births after } \\
\text { previous caesareans } \\
\text { - Special studies on appropriateness of particular types of care (e.g., } \\
\text { prescription drug use by seniors) }\end{array}$ \\
\hline $\begin{array}{l}\text { Competence } \\
\text { The knowledge and skills } \\
\text { of caregivers are } \\
\text { appropriate to the care } \\
\text { that they are providing }\end{array}$ & $\begin{array}{l}\text { - Selected local/provincial records of continuing education, quality } \\
\text { assurance activities, disciplinary proceedings, etc. }\end{array}$ \\
\hline $\begin{array}{l}\text { Continuity } \\
\text { How services fit together - } \\
\text { coordination, integration, } \\
\text { and ease of navigation }\end{array}$ & $\begin{array}{l}\text { Percentage of Canadians who have a regular family doctor by } \\
\text { province } \\
\text { - Local/provincial information on how often formal plans are made for } \\
\text { the care of patients after they leave hospital }\end{array}$ \\
\hline
\end{tabular}


Cont. Annex 5. Canadian Institute of Health Information's Health System Performance Framework: Examples of Existing Measures of Health System Performance

\begin{tabular}{|c|c|}
\hline $\begin{array}{l}\text { Dimension of Health } \\
\text { System Performance }\end{array}$ & Existing Measures \\
\hline $\begin{array}{l}\text { Effectiveness } \\
\text { How well services work } \\
\text { and how they affect our } \\
\text { health }\end{array}$ & $\begin{array}{l}\text { - Measures of how well we prevent disease or its progression } \\
\text { (e.g., infectious disease rates and preventable hospitilizations) } \\
\text { - } \quad \text { Research reports on clinical effectiveness of some treatments } \\
\text { - } \quad \text { Long-term survival for dialysis and transplant patients }\end{array}$ \\
\hline $\begin{array}{l}\text { Efficiency } \\
\text { Achieving best results at } \\
\text { lowest cost }\end{array}$ & $\begin{array}{l}\text { - Actual versus expected length of stay in hospital } \\
\text { - Hospital stays for patients who may not have needed admission } \\
\text { - Comparative data on the cost of physician services } \\
\text { - Local/provincial costs of particular services }\end{array}$ \\
\hline $\begin{array}{l}\text { Safety } \\
\text { Minimising potential risks } \\
\text { of a health environment or } \\
\text { service }\end{array}$ & $\begin{array}{l}\text { - Hip fractures while in health care facilities and in the community } \\
\text { - Workers compensation claims for health sector workers } \\
\text { - Some local info on needle stick injuries, etc. }\end{array}$ \\
\hline
\end{tabular}

Source: CIHI, 2000. 


\section{ANNEX 6. COUNTRY SUMMARY FOR UNITED KINGDOM}

\section{Introduction}

105. Health care in the United Kingdom is provided mainly by the National Health Service (NHS) which is funded mainly from general taxation. The majority of hospitals are publicly owned and managed. General practitioners are independent practitioners but nearly all are contracted to the NHS. The NHS is the responsibility of central government. Consequently, management of the bulk of health care is more centralised than in the publicly funded parts of the health systems in Australia and Canada.

106. As in other developed countries, clinical performance was a matter mainly for self-regulation by the relevant professions. Indeed, because control of overall health expenditure was achieved early in the history of the NHS, Britain may have had more 'clinical freedom' than many other OECD countries.

107. The United Kingdom (UK) has been developing performance measures for the NHS since 1983, at least. The two activities: of developing measures; and of using them to try to influence performance; have been more integrated in the NHS than in the health systems of the other countries covered in this paper. Moreover, there have been three different performance management regimes in England since 1983. Hence, the UK has experienced of a series of experiments in the development and application of performance indicators over nearly two decades.

\section{3-1990}

108. In the 1980s hospital services in the NHS in England were under the direct line management of the Department of Health via Regional and District Health Authorities (RHAs and DHAs). They were integrated, in the sense that DHAs were responsible both for the funding and for the provision of hospital services. The Conservative Government, which came to power in 1979, was determined to improve the management and performance of public hospitals. To that end, it instituted an annual objective setting and performance review process, chaired by Ministers, for RHAs. RHAs were, in turn, to hold DHAs to account. In addition, following the 'Griffiths Review' (1983), decisions were taken to reform the management of hospitals. Unified command by chief executives replaced 'consensus management' (management by agreement between lay administrators, a senior clinician and a senior nurse). Many of the new chief executives were brought in from the private sector.

109. In support of these reforms, a set of 'performance indicators' was developed centrally and published in 1983. Most of the indicators - which were derived from the available administrative statistics were hospital activity, length of stay and cost indicators for DHA's and for individual hospitals. For example, one indicator was the difference between actual and expected average cost per inpatient for each hospital, based on a national regression analysis of variations in average cost per inpatient. These were aimed mainly at the lay managers responsible for RHA's and DHA's.

110. Retrospective analysis of annual changes in hospital 'efficiency' (in the form of an index of changes in cost weighted activity divided by an index of changes in real expenditure on hospital inputs, for England) over the period 1979- 1995 suggests that productivity was fairly flat from 1979-1983. It then started to rise at a rate of about $1.5 \%$ pa for the remainder of the 1980s. It can be suggested that the rise in productivity following 1983 was due in part to the new combination of clearer objectives for, improved 
management of, and better information on, hospital costs and activities. However, changes in clinical practice, such as increased use of day surgery, and improvements in community care - both of which allowed hospital length of stay to fall - are likely to have played a role also.

\section{1-1996}

111. In 1991 major reforms to the NHS were introduced involving, among other things, the separation of the purchasing of hospital services from their provision. There were to be two sorts of purchasers: general practitioner 'fundholders' who could volunteer to hold budgets to purchase selected hospital services and reformed (district) health authorities (HAs) to purchase the remaining services. In addition, hospitals were given more autonomy. Purchasing was to be mediated through annual contracts for services, which allowed performance objectives to be set for hospital services, as well as prices and budgets at a local level. The idea was that in the new 'internal market' hospitals would compete for public funds both on price and on quality. Meanwhile, the Regional and District Health Authorities remained under direct line management by the Department of Health and could be given planning and performance targets and held to account.

112. Measures were also taken to strengthen medical audit at hospital level by providing more resources for clinical, peer group review of practice.

113. Shortly after these reforms, the Government introduced, for the first time, targets for annual improvements in 'efficiency' for the Hospital and Community Health Services, based on the index of efficiency described above. In addition, a 'Patients' Charter' was introduced which included targets for waiting times for non-emergency surgery, among other things. For example an objective was set to ensure that in future no patient should wait more than two years for non-emergency surgery. Various new performance indicators for HAs were collected and published to monitor progress on these targets. These were aimed mainly at the general public. The shortage of indicators of outcome and quality of health care was noted - not for the first time - and long-term work to fill such gaps was continued.

114. Retrospective analysis of the national efficiency index suggests that there was a further acceleration in the rate of improvement of (measured) hospital productivity following these reforms. The rate of increase was about $2 \%$ pa in the first half of the 1990s. By 1995, the gain in measured hospital productivity had caught up with the gain in measured productivity in the UK economy as a whole arguably a notable achievement for a service industry. Most of the explanation for the improvements in hospital productivity lay in sharp increases in rates of day case (same day) surgery and reductions in average length of stay. Again, it can be suggested that the further rises in the index were due in part to the combination of targeting performance and the introduction of new, contractual incentives. There was also considerable success in changing the distribution of waiting times - eliminating the longest waits and bringing down the average wait for those patients on the waiting list. Hospitals seemed to be particularly responsive to GP fundholders.

115. However, by the mid 1990s doubts had begun to set in about the sustainability of repeated annual rises, in excess of the rate of growth of real hospital expenditure, in the volume of hospital activity. There was growing concern at hospital level that the volume of care was being driven up at the expense of quality of care. At the centre, there were increasing worries about gaming in the system. For example, endoscopies which had been labelled as outpatient visits might be re-labelled as day surgery cases, attracting a higher cost weight, thereby boosting the activity index. Meanwhile, little evidence was emerging of the effects of spending more on medical audit, carried on behind closed doors.

116. At about this time the long-term work on the development of selected indicators on outcome and quality began to bear some fruit in that a list of potential indicators emerged which had been agreed with representatives of the medical profession. Given the relative novelty of these indicators, the emphasis was on raising questions about performance rather than on proposing league tables. 


\section{7-2000}

117. The New Labour Government which was elected in May 1997 introduced further reforms both to the management of the NHS and to the performance measurement process. First, in 'The New NHS: Modern, Dependable' (Department of Health, 1998) the Government announced that competition would be abandoned although the purchaser/provider split and contracting for hospital services were to be retained. GP fundholding would be replaced by Primary Care Groups (PCGs), which would involve all GPs in purchasing. PCGs would contain about $50 \mathrm{GPs}$ each, on average. In addition, proposals for a new 'performance framework' were set out, borrowing from the thinking about 'balanced score cards' in the US. In recognition of the criticisms of the efficiency index, a much wider approach was to be adopted including a new emphasis on quality. In particular, various clinical effectiveness and outcome measures were proposed and patient experience was to be measured nationally for the first time via a regular 'Survey of Patient and User Experience'. Performance was to be measured under six domains:

- health improvement

- fair access

- effective delivery of appropriate health care

- efficiency

- $p a t i e n t / c a r e r$ experience of the NHS

- health outcomes of NHS care.

118. Details of the indicators proposed under each of these domains are included in Annex 10, which follows.

119. In 'A First Class Service: Quality in the new NHS' (NHS Executive, 1998) the Government set out further proposals about new arrangements for pursuing quality. There were to be essentially three interrelated processes.

1) The setting of clear standards for services though the development of 'National Service Frameworks' for specific care groups such as the mentally ill, the elderly and people suffering from major acute diseases. In addition a new 'National Institute for Clinical Excellence' would conduct health technology assessments and set out guidelines for the adoption in the NHS of those new treatments which were found to be cost-effective.

2) The pursuit of good clinical governance, through professional self-regulation, and lifelong learning, at a local level.

3) The monitoring of performance through: the new performance framework and through a new 'Commission on Health Improvement' with powers to monitor and support local clinical selfregulation.

120. Before these reforms had had time to have their full effect, it became evident to the Government that the NHS also needed a major injection of public expenditure to deliver the improved performance that was required. The Government declared that, "The NHS has been underfunded for decades". There was disturbing evidence that the UK was falling behind other West European countries in certain indicators of performance such as rates of survival following a diagnosis of cancer. Moreover, waiting times remained long and there were regular 'winter crises' during which some hospitals had difficulties in meeting emergency demand. At about the same time, there were a few alarming revelations about the failure of the institutions of self regulation to halt the activities of a small number of incompetent and errant doctors. 
121. To accompany the spending of extra resources on the NHS, the Government announced that there would be a new 'NHS Plan' to help to ensure that the money was spent productively.

122. The NHS Plan (Department of Health, July 2000) announced among other things that there would be a new relationship between the centre, region and locality in the NHS. The performance assessment framework --, which had applied primarily to health authorities - would be extended to providers, both hospital trusts and primary care groups. The presumption was that people on the frontline would be trusted to deliver. The centre would set standards, monitor performance, put in place a system of inspection and provide back-up to assist modernisation and, where necessary, to correct failure. The new Commission for Health Improvement (CHI) would inspect NHS organisations regularly. There would also be a Modernisation Agency to help spread best practice.

123. New efficiency targets would be introduced to include quality as well as volume aspects of results. There would be further improvements to performance indicators under the new performance framework and responsibility for publishing the measures would be handed to CHI.

124. In addition, performance improvement would be supported by a new system of targets and incentives. In the case of trusts, the targets would be based on the levels of service already being achieved by the best trusts around the country. The Performance Assessment Framework would be used to identify those trusts with the best performance for fair access, cost-effectiveness, outcomes of care, and responsiveness to patients. The cost of providing care in these high performing trusts would become the benchmark for the whole of the NHS. In addition, all NHS organisations would be classified as 'green', 'yellow' or 'red' on the basis of their performance. Red organisation would be those failing to meet a number of the core national targets. 'Yellow' organisations would be those meeting all or most national core targets but would not be in the top 25\% of performance. Green organisation would be those meeting all targets and scoring in the top $25 \%$ of organisations on performance, taking account of 'value added'. The benchmarks would be reviewed periodically.

125. The incentives would be both non financial, 'earned autonomy', and financial. The 'green' organisations would be rewarded with greater management autonomy and national recognition. The 'yellow' organisations would be required to agree plans for improvements with Regional Offices (which had replaced RHA's). The 'red' organisations would have less freedom and would carry out improvements under the oversight of the Modernisation Agency. High performing organisations will also have automatic access to a $£ 500$ million per annum National Health Performance Fund which will be used to reward progress against annually agreed objectives.

126. The Government has also strengthened the powers of the medical professions' main regulatory body - the General Medical Council and has arranged for better representation of consumers.

\section{Conclusion}

127. It remains to be seen to what extent these new arrangements - which will be accompanied by an increase of about one-third in real spending on the NHS over the next five years - will affect measured performance in the NHS. The new arrangements represent not only a broadening of the measurement of performance but also the introduction of new institutions and new incentives for influencing performance. In particular, the traditional division of labour between professional self regulation of quality and lay management of the remaining aspects of performance, has been revised to make the former more open to outside scrutiny and influence. 


\section{ANNEX 7. NHS HIGH-LEVEL PERFORMANCE FRAMEWORK}

\section{Health Improvement}

Deaths from all causes

(i) Standardised all cause mortality ratio (ages 15-64).

(ii) Standardised all cause mortality ratio (ages 65-74).

(iii) Cancer registrations - the summation of age and sex-standardised rates for the following cancers:

- malignant neoplasm of the stomach;

- malignant neoplasm of small intestine, colon, rectum, rectosignmoid junction and anus;

- malignant neoplasm of trachea, bronchus, and lung;

- malignant melanoma of the skin;

- other malignant neoplasm of female breast;

- malignant neoplasm of cervix uteri.

(iv) Deaths from malignant neoplasms

- death rates from all malignant neoplasms (people aged under 75).

(v) Deaths from all circulatory diseases

- death rates from all circulatory diseases (people aged under 75).

(vi) Suicide rates

- death rates from suicide and undetermined injury.

(vii) Deaths from accidents

- standardised mortality ratios from accidents and adverse effects.

\section{Fair Access}

(i) Surgery rates, composite consisting of age-standardised elective rates for:

- CABG and PTCA;

- hip replacement (aged 65 or over);

- knee replacement (aged 65 or over);

- cataract replacement.

(ii) Size of inpatient waiting list per head of population (weighted).

(iii) Adults registered with an NHS dentist. 
(iv) Children registered with an NHS dentist.

(v) Early detection of cancer, composite consisting of:

- $\%$ of target population screened for breast cancer;

- $\%$ of target population screened for cervical cancer.

\section{Effective Delivery of Appropriate Healthcare}

(i) Disease prevention and health promotion

- $\%$ of target population vaccinated.

(ii) Early detection of cancer, composite consisting of:

- $\%$ of target population screened for breast cancer (ages 50-64);

- \%of target population screened for cervical cancer (ages 25-64).

(iii) Inappropriately used surgery, composite consisting of age standardised:

- rates of D\&Cs performed in women under 40;

- surgical intervention rates for glue ear (grommet surgery).

(iv) Surgery rates, composite consisting of age standardised elective rates for:

- CABG and PTCA;

- hip replacement (ages 65 and over);

- knee replacement (ages 65 and over);

- cataract replacement.

(v) Acute care management, composite consisting of age standardised admission rates for:a

- severe ENT infection;

- kidney/urinary tract infection;

- heart failure.

(vi) Chronic care management, composite consisting of age standardised admission rates for:

- asthma;

- diabetes;

- epilepsy.

(vii) Mental health in primary care

- volume of benzodiazepines.

(viii) Cost effective prescribing composite, consisting of:

- NIC/PU of combination products;

- NIC/PU of modified release products;

- NIC/PU of drugs of limited clinical value;

- NIC/DDD of inhaled corticosteroids.

(ix) Discharge from hospital, composite consisting of:

- rate of discharge to usual place of residence within 56 days of emergency admission from there with a stroke (ages 50 and over);

- rate of discharge to usual place of residence within 28 days of emergency admission from these with a fractured neck of femur (ages 65 and over). 
DEELSA/ELSA/WD(2000)8

\section{Efficiency}

(i) Day case rate.

(ii) Casemix adjusted length of stay.

(iii) Unit cost of maternity (adjusted for casemix and market forces).

(iv) Unit cost of caring for patients in receipt of specialist mental health services (adjusted for casemix, quality and market forces).

(v) $\%$ of generic prescribing.

\section{Patient/Carer Experience of the NHS}

(i) Patients who wait less than 2 hours for emergency admissions (through A\&E).

(ii) Patients with operations cancelled for non-medical reasons on the day of, or after, admission.

(iii) Delayed discharge from hospital for people aged 75 or over, per 1,000 of those aged 75 or over and not in hospital.

(iv) First outpatient appointments for which patient did not attend, percentage.

(v) Percentage of outpatients seen within 13 weeks of GP referral.

(vi) Percentage of those on waiting list waiting 12 months or more.

\section{Health Outcomes of NHS care}

(i) Conceptions below age 16 (rate, girls aged 13-15).

(ii) Decayed, missing and filed teeth in five year olds, average number.

(iii) Adverse events/complications of treatment composite, consisting of age standardised:

- 28 day emergency readmission rates;

- rates of surgery for hernia recurrence.

(iv) Emergency admissions to hospital for people aged 75 or over, per 1000 population.

(v) Emergency psychiatric readmission rates.

(vi) Infant mortality composite, consisting of:

- stillbirth rates;

- infant mortality rates.

(vii) Cancer 5 year survival rates - composite indicator, consisting of age standardised:

- survival rates from breast cancer (ages 15-99);

- survival rates from cervical cancer (ages 15-99). 
(viii) Potentially avoidable mortality composite, consisting of

(with age and sex standardisation where possible):

- mortality from peptic ulcer (ages 25-74);

- mortality rate from fracture of skull and intracranial injury (ages $1+$ );

- maternal mortality (ages 15-44);

- mortality from tuberculosis (ages 5-64);

- mortality from Hodgkin's disease (ages 5-64);

- mortality from chronic rheumatic heart disease (ages 5-44);

- mortality from hypertensive and cerebrovascular disease (ages 35-64);

- mortality from asthma (ages 5-44);

- mortality from appendicitis, abdominal hernia, cholelithiasis and cholecystitis (ages 5-64);

- mortality from CHD in persons under 65.

(ix) In-hospital premature deaths, composite consisting of age standardised:

- 30 day perioperative mortality rate;

- 30 day mortality rates following myocardial infarction (MI) (ages 50 and over). 


\section{ANNEX 8. COUNTRY SUMMARY FOR THE UNITED STATES}

128. The United States, with its mixed public-private health care financing and delivery arrangements, have been considered the leader in this area of performance measurement and monitoring by many experts. To date, much of this effort has been focused on developing performance indicators for use on the clinician level and in health maintenance organisations. However, the existing programmes related to performance measurement in the United States are highly fragmented and uncoordinated across levels of care and across both public and private sectors.

129. There is no uniform national performance measurement framework at this time. Based on recommendations from the Institute of Medicine and the President's Advisory Commission on Quality in 1999, government authorities on the national level intend to explore the use of performance measurement on the population level, while simultaneously coordinating activities between and across public and private sectors.

130. Since the mid-1980s, the private sector - which includes health care providers, managed care organisations and insurers, corporate purchasers of care, accreditation organisations, and consumer groups- has been the driving force behind the trend toward performance measurement and management. Most of the innovation in the private sector activity has been spearheaded by the accreditation agencies such as the National Committee on Quality Assurance (NCQA) and Joint Commission of Healthcare Organisations (JCAHO) and the employers -often in the form of large employer purchasing networks.

131. Accreditation in the U.S. historically grew out of the provider community's interest in defining standards for itself, and this industry has been the province of private voluntary organisations allied with the associated provider groups. The accreditation organisations developed standards that represent best practices of the industry or provider type, traditionally focusing on the quality assurance of the structures of health care. One of the oldest accreditation organisation is the Joint Commission on Accreditation of Healthcare Organisation (JCAHO), founded in 1952 to establish standards for hospitals. JCAHO is currently involved with accreditation standards for a substantially broader array of providers, such as hospitals, long term and ambulatory care facilities, home care organisations, and clinical laboratories. They currently have the authority to terminate hospitals' participation in the Medicare programme if the quality of care is proven to be deficient.

132. In the past, JCAHO concentrated on more structural and process standards rather than health outcomes and quality of care. There have been attempts to identify outcomes-based standards that would allow the public to compare hospitals. However, due to resistance from the hospitals, this effort has been refined to be the ORYX programme, introduced in February 1997. Under the ORYX programme, hospitals and long term care facilities applying for accreditation are required to choose at least six quality indicators from a universe of existing performance measures (found in the inventory of JCAHO's healthcare library of indicators) and report performance on these indicators to JCAHO. The original requirement has been increased over time from two to four to six clinical measures. (JCAHO, 2000). These ORYX requirements, in the future, will be introduced for networks (e.g. organisations that contract with or are part of health plans, integrated delivery networks, provider-sponsored organisations).

133. JCAHO's principal intent is to identify, rather than develop, sound nationally standardised performance measures that support the objectives of the ORYX initiative. In early 1999, the Joint 
Commission gathered a group of stakeholders to provide input on potential focus areas for these so-called "core measures". Stakeholders identified five initial core measurement areas: acute myocardial infarction (including coronary artery disease); congestive heart failure; pneumonia; surgical procedures and complications; and pregnancy and related conditions (including newborn and maternal care). Measures will be drawn up based on the "Attributes of Core Measures and Associated Criteria," which was developed by their Advisory Council on Performance Measurement. These criteria focus on aspects of performance such as:

- availability/access;

- appropriateness;

- continuity;

- effectiveness;

- efficacy;

- efficiency;

- prevention/early detection;

- safety;

- respect/caring;

- timeliness.

134. These indicator groups then contain three measurement categories including: clinical performance; patient perception (satisfaction); health status; and administrative/financial. The JCAHO projects that hospitals and long term care organisations could begin collecting these core measures as early as 2002 .

135. There is also another standard-setting group, called the National Committee for Quality Assurance (NCQA), a private non-profit group committed to improving the quality of managed care organisations. In 1990, NCQA was originally set up as an advocacy group for managed care organisations. Now, NCQA has evolved in its purpose and currently pursues two main activities:

1) voluntary accreditation of health plans and;

2) development and publication of the Health Plan Employer Data and Information Set (HEDIS) - a set of indicators to be used by health plans to measure different aspects of their health care services.

136. NCQA's set of HEDIS indicators currently is in its third version with more than 60 performance indicators covering quality, access to and satisfaction with care, membership and use of services, finance and management (Annex 12). Since its inception, it has become a tool for large purchasers of care employers -- and health plans who have incorporated these performance measures into their quality improvement programmes. Though their quality and access indicators have been influential, HEDIS indicators have been criticised in that they really only measure the administrative performance or use of services rather than quality or outcome of the services (Epstein, 1995; Meyer et. al., 1998). While these indicators mainly measure process of care, there are only two indicators of outcome - low birth weight or a proxy for a health outcome (hospitalisation for patients with asthma) (Epstein, 1995). Additional criticisms focus on the fact that these indicators are not risk-adjusted.

137. Health plans may decide whether they wish to publicly release their profiles based on the HEDIS indicators. In 1997, 292 plans (45 percent) permitted public reporting of the data. According to NCQA, the plans that refuse to allow publication of HEDIS tend to be those with significantly lower scores than the plans who permit publication (Bodenheimer, 1999). In future versions, indicators for treating acute and chronic disease and special populations such as the elderly are intended to be included so to better address the concerns of Medicaid and Medicare as purchasers of health plan services. 
138. Since 1990, more than half of the health maintenance organisations in the US have requested accreditation surveys from NCQA - with many of the plans using the HEDIS quality measures. This trend is due to the increasingly competitive managed care environment in the late 1980s and 1990s. Employers must select carefully the health plan that offers the most "value for money" for their employees. There was concern among employers that health plans might skimp on quality and services to offer the lowest premiums. As a result of these concerns, several large employers made it a policy not to contract with health plans that have yet to receive accreditation. In turn, health plans felt the pressure to seek accreditation or to lose their enrollees and market share.

139. This marked the beginning of a trend where several employers and employers' groups started to experiment using their market power as a force to promote quality and value for money in health care services rather than focusing their attention exclusively on costs. In fact, it is only experimentation taking place in the US among most purchasers. Despite all of the talk to focus on quality, a report, conducted by the Agency for Health Care Quality and Research found that most employers in the US are still primarily focusing on costs in their selection of health plans, while only a few large corporations and business coalitions are actually implementing the principles of value-based purchasing - where buyers hold providers of health care accountable for both cost and quality (Meyer et. al., 1999).

140. Findings of this report highlighted that most employers might be requesting performance measures from health plans, however, very few are actually looking at the results and using them in their contracting decisions. Part of the problem may lie in the fact that organisations are at a very early stage of collecting this information so the quality of the data is in question. The report uncovered the few so-called pioneers who have taken brave sets to consistently use performance information to influence decisions. Some are encouraging health plan's participation in quality management and improvement initiatives and pricing these plans more favourably so employees will be encouraged to enroll the high performing plans. A handful are even using financial incentives for health plans to provide data. In the short term, there is hope to link payment of the premiums to improvement in performance, and not simply the delivery of data.

141. There is another organisation called the Foundation for Accountability (FACCT) -created in 1995. FAACT is a not-for-profit coalition of purchasers and consumer organisations whose primary mission is to enable purchasers and consumers to make informed choices. FAACT has developed a framework for quality information organised into five categories reflecting how consumers think about their care: the basics (e.g. access and coordination of care), staying healthy, getting better, living with illness, and changing needs, which can be used to evaluate the delivery of care regardless of organisational structure. They have also created indicators based on common and costly conditions with a focus on health outcomes such as: adult asthma, diabetes, breast cancer, major depression, and low back pain. While no purchaser is currently using these measures, there appears to be interest in participating in the pilot projects being established by RAND Corporation - with funding from HCFA.

142. In the public sector, there remains no articulated national strategy to monitor performance of the government-supported health care insurance programmes. In the last two years, however, the need for such a strategy has risen on the agenda. In the mid-1980s, the U.S. Health Care Financing Administration (HCFA) took a first step towards public release of performance measurement with its publication of national risk-adjusted hospital mortality rates. While ultimately discontinued by HCFA in 1993 after much criticism, the national hospital mortality rates project inspired other efforts to assess performance through measurement of outcomes. In the mid-1980s, there were several state initiatives to collect and publish severity adjusted performance data on outcomes in Maryland, Pennsylvania, and New York.

143. A group of seven Maryland hospitals in 1985 voluntarily initiated the exploration of 10 inpatient care indicators. Since then, over 1,000 hospitals are participating in the project after developing two sets of indicators for inpatient and ambulatory care plus initiating development of four new sets of indicators: pediatric care, long term care, psychiatric care and process of care indicators. Unlike the set of indicators created in other states (see below), Maryland's indicators are mainly used for internal use within the 
hospitals to identify problem areas and shortcomings in their processes of care and is not used for external reporting to the public. (Kazandjian et. al., 1995).

144. During the late 1980s and early 1990s, the states of New York and Pennsylvania started to present public information on mortality rates associated with coronary artery bypass surgery. New York State's work in this area has become a model for many states - who have since following suit in recent years such as New Jersey and California. In 1985, New York required provider organisations to submit detailed information on each CABG procedure in the state and calculated risk-adjusted mortality rates for hospitals and practitioners. The first report publishing these hospital mortality rates was released in 1990 and in 1992, a similar report was presented covering the activity of individual practitioners. In 1986, Pennsylvania Health Care Cost Containment Council (PHC4) also created a similar program to comply to legislation passed required that data about the quality of care be made public (Pennsylvania Act 19861989) and that all hospitals collect data according to a standard system which allowed comparison of predicted with actual deaths. Its first report, released in 1992, presented findings on the following indicators, same as in NY:

- risk-adjusted in-hospital mortality rates associated with $\mathrm{CABG}$,

- average hospital charge associated with CABG, and

- risk-adjusted length of stay after surgery for coronary artery bypass patients, according to hospital where surgeries were performed and cardiac surgeon.

145. In addition, the state of Massachusetts has instituted a program that has demonstrated a successful framework for measuring and disseminating comparative quality information about patient's hospital experiences, building upon some agreed public release principles (Rogers and Smith 1999). Other states which have developed performance measurement efforts are Rhode Island and Vermont.

146. There has been a fair amount of debate over the effect of the New York and Pennsylvania programmes in reducing surgical mortality. Some believe that reported data demonstrates a significant decrease in surgical mortality; while others argue that similar decreases in mortality have occurred in states with no programme of this type and in the country as a whole (Jencks, 2000). Moreover, there are questions as to how much this data has impacted providers' clinical decisions or even patients' choices. Reports have found that New York practitioners were slightly familiar with the data and that a majority of cardiologists had not changed their referral practices because of the data. (Hannan et. al.,. 1997) Another study found that there was almost no impact of outcomes reports on physician referral practices or patient choices in Pennsylvania (Schneider and Epstein, 1996; Schneider and Epstein, 1998).

147. In a wider review of published evaluations of seven different quality reporting systems across the US (Marshall et. al., 2000), it was pointed out that the expected gains of public disclosure of quality information have not been made clear. Moreover, both the benefits and the risks had received minimal empirical investigation. The published studies that did exist suggested that public disclosure of performance data for hospitals, health care professionals and health care organisations had little effect on the behaviour of consumers or purchasers. Individual physicians were also sceptical, perceiving adverse side effects of disclosure. For example, following the publication of surgeon-specific CABG mortality rates in Pennsylvania, referred to above, almost two-thirds of cardiologists reported increasing problems in finding surgeons to operate on high-risk patients. A similar proportion of cardiac surgeons reported that they were less willing to operate on such patients. However, provider organisations, in particular hospitals, seemed to be more responsive to such disclosures. In New York, the CABG mortality rate declined much more steeply than the national average following public disclosure. Hospitals may have withdrawn admitting privileges from low volume, high-risk surgeons. They may also have put pressure on other surgeons to improve their performance. The authors of the literature review concluded that health care performance data is likely to be of most use if it is directed at organisational providers. Similar observations about 'closing the loop' by feeding back performance information directly to providers have 
been made by Legnini et. al., 2000. The suggestion seems to be that external review may work best if it is used to complement and reinforce peer review.

148. On the national level, while there are several programmes underway with the different national health agencies, there is yet to be a comprehensive national plan for performance measurement and monitoring. One of the main government players in performance measurement is the Health Care Financing Administration, which oversees the two government-supported health care insurance programmes, Medicare and Medicaid and monitors the performance of the programmes. HCFA uses performance measures to achieve the Agency's mission of:

1) providing consumer information that assists beneficiaries in making choices in health care,

2) setting process and outcome criteria to which plans/ providers are held accountable, and

3) facilitating quality improvement activities at the program level focusing on national Medicare/Medicaid key clinical priorities at the plan and provider level (HCFA, 2000).

149. Since the 1990s, HCFA has started to adopt some private-sector style performance measurement and applied these practices to their governmental programmes, particularly with the emergence of more managed care arrangements into these national programmes. This has also paralleled HCFA's evolving role from a payer of bills to a more active purchaser of care for Medicare and Medicaid enrollees. For instance, HCFA has announced that it would require all Medicare managed care organisations to report using indicators from the HEDIS data set; while states have the option of using HEDIS to monitor the performance of its Medicaid programme. As part of this program, HCFA also requires that Medicare HEDIS data be audited to gain detailed insights into data strengths and weaknesses, identify areas for improvement, and imbue the public with a sense of confidence as to the usefulness of the performance data.

150. In addition to HEDIS data, HCFA also hopes to collect survey data for performance of its Medicare health plans using the Health Outcomes Survey (formerly Health of Seniors), which measures the functional status from the patient's point of view using the SF-36 and also the Consumer Assessment for Health Plan Study (CAHPS) (see below for further information). HCFA requires Medicare plans to participate in this standardized satisfaction survey of their beneficiaries. For its fee-for-service arrangements in Medicare, HCFA is testing the feasibility of using subsets of the HEDIS measures in FFS at the national, small geographic and large group practice level and the Medicare Health Outcomes Survey is also being pilot-tested in this project.

151. In 1992, HCFA launched the Health Care Quality Improvement Projects (HCQIP) in collaboration with the Peer Review Organisations in an effort to improve care with the development and use of quality indicators. The project began with the Cooperative Cardiovascular Project, focusing on AMI. Since then, it has expanded to six other clinical priorities, four of which primarily involve inpatient quality measures: acute myocardial infarction (AMI), heart failure (HF), stroke/atrial fibrillation, and pneumonia/influenza. Using administrative claims data to identify cases, a sample of hospital charts will be abstracted in each state and evaluated for performance on the established measures. On the outpatient side, state-specific performance will be focused on the delivery of influenza immunizations, pneumococcal polysaccharide vaccinations, mammograms and care for people with diabetes. The list of quality indicators are presented in Annex 10.

152. HCFA is also exploring the concept of requiring Medicare participating hospitals to report on a national standardized set of performance measures. HCFA will work with the State of Rhode Island and the National Forum for Health Care Quality Measurement and Reporting, hospital associations, and accrediting organizations to standardize a core set of hospital performance measures. During this initial 
stage, HCFA plans to apply the learnings from the HCQIP Program by using the performance measures for pneumonia, heart failure, stroke and myocardial infarction as a starting point to initiate this effort.

153. Formerly known as the Agency for Health Care Policy and Research, the Agency for Health Care Research and Quality (AHRQ) is the other national agency with a primary focus on the development of performance measurement. Several projects are underway to explore this aim such as the Computerised Needs-Oriented Quality Measurement Evaluation System (CONQUEST). CONQUEST serves as a database of measures being used in public and private sectors. It is intended to assist users identify existing measures, understand the characteristics of individual measures, compare measures using a common set of factors, and determine which measures are best suited to user's particular purpose.

154. One other project being led by AHRQ is the Q-Span project. This project's goal is to strengthen the science base of quality measurement while expanding the scope and availability of validated, ready-touse measures. Q-SPAN builds on past work in quality measurement by public and private organisations through eight cooperative agreements to develop and test clinical performance measures. The areas covered by the Q-SPAN project include dental care, asthma, adult care over age 50, cardiovascular diseases, hip fractures, diabetes, breast cancer, subacute and home care as well as general development of HEDIS measures.

155. Under the auspices of AHRQ, there is also the project on healthcare cost and utilisation (HCUP) quality indicators which comprise a set of 33 clinical performance measures for the use of hospitals of inpatient quality of care as well as state and community assessments of access to care. (Johantgen, M. et. al., 1998) These indicators are considered a low-cost approach to meeting short-term information needs as they are based on existing sources of data such as administrative data on inpatient stays. These indicators can be used at various levels either hospitals and hospital systems, community and state level, etc. They span three dimensions:

- potentially avoidable adverse hospital outcomes;

- potentially inappropriate utilisation of hospital procedures (concerns of overuse and underuse); and

- potentially avoidable hospital admissions.

156. AHRQ has sponsored a project called Consumer Assessment of Health Plans (CAHPS). CAHPS is an initiative to collect and report information on consumer's experiences in getting care through their health plans. The developmental work for CAHPS is done at AHRQ, with applications for Medicare, Medicaid, and commercial populations. In mid 2000, HCFA was fielding the fourth round of CAHPS in the Medicare population. They sample approximately 600 beneficiaries per health plan to be in the survey each year (total sample of about 200,000 beneficiaries each year). The survey asks respondents to give reports and ratings of care they received through the plan. Results are summarised by plan and selected measures are made available to the public on Medicare's website and in a handbook on Medicare that is mailed to all 39 million beneficiaries each year. The intent is to provide data on the quality of plan performance (selected HEDIS data are also provided) that can be used with information on costs and covered benefits to help Medicare beneficiaries make an informed choice among health plans. HCFA also provides reports back to the health plans that summarise all of their CAHPS results with benchmarks to other plans in their area for quality improvement purposes. HCFA is expanding the Medicare health plan. CAPHS-related efforts are also going on for selected Medicaid and commercial populations. AHRQ has created a centralised National CAHPS Benchmarking Database (NCBD) that houses CAHPS data for Medicare, Medicaid, and commercial populations. The NCBD supports the production of analyses and reports about health plan performance both within and between population groups.

157. AHRQ recently received a congressional mandate to produce and annual report to the nation on health care quality. The National Quality Report (NQR) will include a broad set of performance measures that will be used to monitor the nation's progress toward improved health care quality. It is hoped that the 
NQR will serve a number of purposes, such as providing: (1) concrete evidence that demonstrates the validity of concerns (or lack thereof) about quality of care and target areas for improvement; (2) the ability to document whether health care quality is stable, improving, or declining over time; and (3) national benchmarks against which specific states, health plans, and providers can compare their performance. The first report is due to Congress in FY 2003 (which ends on 30 September 2003) and annually thereafter.

158. Related to the National Quality Report, AHRQ also received a congressinoal mandate to produce an annual report on disparities in health care delivery. AHRQ's disparities report will help move the U.S. in the direction of tracking equity in health care. It is planned to include measures of disparity in health care delivery for priority populations such as low-income groups, minority groups, women, children, the elderly, and individuals with special health care needs. The first report is scheduled for completion in FY 2003 and will be produced annually thereafter.

159. In 1998, two major national reports were released, which appeared to put performance high on the agenda. The first was the one released by the President's Advisory Commission on Consumer Protection and Quality in the Health Care Industry - entitled, "Quality First: Better Health Care for All Americans" and the second was the report released by the Institute of Medicine National Roundtable on Health Care Quality. In this report, the commission advocated a framework for quality measurement that would capture multiple dimensions of quality and suggested a focus on of three dimensions:

- technical quality-use of judgement, skill and available technology to improve the health of patients;

- accessibility-ease with which health care can be reached in the face of financial, geographical, organisational, cultural and emotional barriers; and

- acceptability-the degree to which health care satisfies patients.

160. The President's Commission has also created two organisations who would jointly work together representing private and public sectors respectively: first, the Forum for Health Care Quality Measurement and Reporting and the second Advisory Council on Health Care Quality. The President has called on Congress to create a Quality Council through legislation to establish national goals to improve health care quality and develop strategies to achieve them. Meanwhile, in late 1998, the Quality Forum met to identify its mission, governance and financing. In March 1999, the Quality Forum released its mission, stating the following goals:

- creation of an intellectual framework for quality measurement;

- standardisation of quality measurement by endorsing common sets of measures for national use;

- public access to valid, comparative data;

- use of the data to facilitate improvement by health care providers and plans, inform consumer and purchaser choice, and stimulate market demand for quality improvement.

161. The Quality Forum plans to gather stakeholders from key organisations such as JCAHO, NCQA, and FAACT. In addition, the President's Advisory Commission set up the Quality Interagency Coordination Task Force (QuIC) to ensure that all federal agencies involved in performance and quality measurement work on common goal in coordination. One of the workgroups - led by the AHRQ and HCFA-- has produced an inventory of all system-wide performance measures (clinical, population, and health system) developed, in use, or under development by Agencies and Departments within the Federal Government to be used by the Measures Workgroup. Additionally, legislation was awaited at the time of preparing this report to make these processes formal and official, but it had not yet been passed. 


\section{ANNEX 9. UNITED STATES' NATIONAL COMMITTEE QUALITY ASSURANCE'S HEDIS MEASURES}

\section{Effectiveness of Care}

- Advising smokers to quit (in Member Satisfaction Survey)

- Beta blocker treatment after a heart attack

- The health of seniors

- Eye exams for people with diabetes

- Flu shots for older adults

- Cervical cancer screening

- Breast cancer screening

- Childhood immunisation status

- Adolescent immunisation status

- Treating children's ear infections

- Prenatal care in the first trimester

- Low birth-weight babies

- Check-ups after delivery

- Follow up after hospitalisation for mental illness

\section{Access/Availability of Care}

- Availability of primary care providers

- Children's access to primary care providers

- Availability of mental health/chemical dependency providers (phased in)

- Annual dental visit

- Availability of dentists

- Adults' access to preventive/ambulatory health services

- Initiation of prenatal care (phased in)

- Availability of obstetrical/prenatal care providers (phased in)

- Low birth-weight deliveries at facilities for high-risk deliveries and neonates

- Availability of language interpretation services

\section{Satisfaction with the Experience of Care}

- The Member Satisfaction Survey (numerous measures)

- Survey descriptive information 


\section{Health Plan Stability}

- Disenrollment

- Provider turnover

- Narrative information on rate trends, financial stability and insolvency protection

- Indicators of financial stability

- Years in business/total membership

\section{Use of Services}

- Well-child visits in the first 15 months of life (phased in)

- Well-child visits in the third, fourth, fifth and sixth year of life (phased in)

- Adolescent well-care visit (phased in)

- Frequency of selected procedures

- Inpatient utilisation -- non-acute care

- Inpatient utilisation -- general hospital/acute care

- Ambulatory care

- Caesarean section and vaginal birth after caesarean rate (VBAC - rate)

- Discharge and average length of stay for females in maternity care

- Births and average length of stay, newborns

- Frequency of ongoing prenatal care

- Mental health utilisation -- percentage of members receiving inpatient day/night and ambulatory services

- Readmissions for specified mental health disorders

- Chemical dependency utilisation -- inpatient discharges and average length of stay

- Chemical dependency utilisation -- percentage of members receiving inpatient, day/night care and ambulatory services

- Mental health utilisation - inpatient discharges and average length of stay

- Readmission for chemical dependency

- Outpatient drug utilisation

\section{Cost of Care}

- High-occurrence/high-cost DRGs

- Rate trends

\section{Informed Health Care Choices}

- Language translation services

- New member orientation/education

\section{Health Plan Descriptive Information}

- Board certification/residency completion

- Provider compensation

- Physicians under capitation

- Recredentialing

- Paediatric mental health network 
- Chemical dependency services

- Arrangements with public health, educational and social service organisations

- Weeks of pregnancy at time of enrolment

- Family planning services

- Preventive care and health promotion

- Quality assessment and improvement

- Case management

- Utilisation management

- Risk management

- Diversity of Medicaid membership

- Unduplicated Count of Medicaid members

- Enrolment by payer (member years/months)

- Total Enrolment 


\section{ANNEX 10. US HCFA QUALITY INDICATORS FOR MEDICARE'S HEALTH CARE QUALITY IMPROVEMENT PROGRAM}

\section{Acute Myocardial Infarction}

- Early administration of aspirin

- Early administration of beta-blocker

- Timely reperfusion

- Aspirin at discharge

- Beta-blocker at discharge

- ACEI at discharge for low left ventricular ejection fraction

- Smoking cessation counseling during hospitalization

\section{Breast Cancer}

- Biennial mammography screening

\section{Diabetes}

- Biennial retinal exam by an eye professional

- Annual HbA1c testing

- Biennial lipid profile

\section{Heart Failure}

- Appropriate use/non-use of ACEI at discharge (excluding discharges on ARB)

\section{Pneumonia}

- Influenza vaccinations

- Pneumococcal vaccinations

- Blood culture before antibiotics are administered

- Appropriate initial empiric antibiotic selection

- Initial antibiotic dose within 8 hours of hospital arrival

- Influenza vaccination or appropriate screening

- Pneumococcal vaccination or appropriate screening

\section{Stroke}

- Discharged on antithrombotic (acute stroke or TIA)

- Discharged on warfarin (atrial fibrillation)

- Avoidance of sublingual nifedipine (acute stroke) 


\section{LABOUR MARKET AND SOCIAL POLICY OCCASIONAL PAPERS}

Most recent releases are:

No. 46 EXPLORING THE EFFECTS OF HEALTH CARE ON MORTALITY ACROSS OECD COUNTRIES (2000) Zeynep Or

No. 45 TRENDS IN WORKING HOURS IN OECD COUNTRIES (2000) John M. Evans, Douglas C. Lippoldt, Pascal Marianna (forthcoming)

No. 44 AN INVENTORY OF HEALTH AND DISABILLITY-RELATED SURVEYS IN OECD COUNTRIES (2000) Claire Gudex and Gaetan Lafortune

No. 43 INTERNATIONAL TRADE AND CORE LABOUR STANDARDS - A SURVEY OF THE RECENT LITERATURE (2000) Drusilla K. Brown

No. 42 TRENDS AND DRIVING FACTORS IN INCOME DISTRIBUTION AND POVERTY IN THE OECD AREA (2000) M. Förster, assisted by M. Pellizzari

No. 41 CARE ALLOWANCES FOR THE FRAIL ELDERLY AND THEIR IMPACT ON WOMEN CARE-GIVERS (2000) J. Jenson and S. Jacobzone

No. 40 PHARMACEUTICAL POLICIES IN OECD COUNTRIES: RECONCILING SOCIAL AND INDUSTRIAL GOALS (2000) Stephane Jacobzone

No. 39 NET SOCIAL EXPENDITURE (1999) Willem Adema

No. 38 AGEING AND CARE FOR FRAIL ELDERLY PERSONS: AN OVERVIEW OF INTERNATIONAL PERSPECTIVES (1999) Stéphane Jacobzone

No. 37 THE HEALTH OF OLDER PERSONS IN OECD COUNTRIES: IS IT IMPROVING FAST ENOUGH TO COMPENSATE FOR POPULATION AGEING? (1998) S. Jacobzone, E. Cambois, E. Chaplain, J.M. Robine

No. 36 HEALTH OUTCOMES IN OECD COUNTRIES: A FRAMEWORK OF HEALTH INDICATORS FOR OUTCOME-ORIENTED POLICYMAKING (1998) Melissa Jee and Zeynep Or

No. 35 WHAT WORKS AMONG ACTIVE LABOUR MARKET POLICIES: EVIDENCE FROM OECD COUNTRIES' EXPERIENCES (1998) John Martin

No. 34 MEASURES OF JOB SATISFACTION - WHAT MAKES A GOOD JOB? EVIDENCE FROM OECD COUNTRIES (1998) Andrew E. Clark (available in French)

No. 33 SOCIAL AND HEALTH POLICIES IN OECD COUNTRIES: A SURVEY OF CURRENT PROGRAMMES AND RECENT DEVELOPMENTS [Text and Annex] (1998) D.W. Kalisch, T. Aman and L. A. Buchele

A complete list of available papers can be found on the internet site: http://www.oecd.org/els/social/docs.htm, through which recent papers can be accessed directly. To receive a paper copy of this list or any particular papers, please send your name, organisation and full address to:

Labour Market and Social Policy Occasional Papers

Directorate for Education, Employment, Labour and Social Affairs

OECD, 2, rue André-Pascal, 75775 PARIS CEDEX 16, FRANCE

Mailing List for free of charge Labour Market and Social Policy Occasional Papers

Please include the following name on the mailing list:

(write in capitals)

Name

Organisation

Address 
DEELSA/ELSA/WD(2000)8

\section{RECENT OECD PUBLICATIONS IN THIS FIELD INCLUDE:}

REFORMS FOR AN AGEING SOCIETY (2000)

PUSHING AHEAD WITH REFORM IN KOREA: LABOUR MARKET AND SOCIAL SAFETY-NET POLICIES (2000)

A SYSTEM OF HEALTH ACCOUNTS (2000)

OECD ECONOMIC STUDIES No. 31, 2000/2 (Special issue on “Making Work Pay") (2000)

POLICIES TOWARDS FULL EMPLOYMENT (OECD Proceedings) (2000)

LABOUR MIGRATION AND THE RECENT FINANCIAL CRISIS IN ASIA:

(OECD Conference Proceedings) (2000)

OECD SOCIAL EXPENDITURE DATABASE, 1980-1996 (1999)

available in English and French on CD-ROM

OECD HEALTH DATA (2000)

available in English, French, Spanish and German on CD-ROM (Windows 95, 98, 2000 or NT)

A CARING WORLD - The New Social Policy Agenda (1999)

MAINTAINING PROSPERITY IN AN AGEING SOCIETY (1998)

THE BATTLE AGAINST EXCLUSION - Volume 3

Social Assistance in Canada and Switzerland (1999)

THE BATTLE AGAINST EXCLUSION - Volume 2

Social Assistance in Belgium, the Czech Republic, the Netherlands and Norway (1998)

THE BATTLE AGAINST EXCLUSION

Social Assistance in Australia, Finland, Sweden and the United Kingdom (1998)

OECD EMPLOYMENT OUTLOOK June 2000 (published annually)

THE PUBLIC EMPLOYMENT SERVICE IN THE UNITED STATES (1999)

BENEFIT SYSTEMS AND WORK INCENTIVES (1999)

For a full list, consult the OECD On-Line Bookstore on: http://www.oecd.org or write for a free written catalogue to the following address:

OECD Publications Service

2, rue André-Pascal, 75775 PARIS CEDEX 16

or to the OECD Distributor in your country 